\title{
1 THE VARIABILITY OF VOLATILE ORGANIC COMPOUNDS IN CLINICAL ENVIRONMENTS.
}

2 Dahlia Salmana, Wadah Ibrahim ${ }^{b, c}$, Amisha Kanabara, Bo Zhaob,c, Amisha Singapurib,c, Michael $3 W^{2}$ Wilded $^{d}$ Rebecca L Cordelld, Teresa McNallyb, Dorota Ruszkiewicza, Andria Hadjitheklia, Robert Free ${ }^{b, c}$, $4 \quad$ Neil Greeningb,c, Erol A Gaillardb, Caroline Beardsmoreb, Paul Monks ${ }^{d}$, Chris Brightlingb,c, Salman

5 Siddiquib,c, C L Paul Thomasa* On behalf of the EMBER consortium

6 *Corresponding author: C.L.P.Thomas@lboro.ac.uk

7 a Department of Chemistry, Loughborough University, Loughborough, LE11 3TU, UK.

8 b College of Life Sciences, Department of Respiratory Sciences, University of Leicester, $9 \quad$ University Road, Leicester LE1 7RH

10 c Leicester NIHR Biomedical Research Centre (Respiratory theme), Glenfield Hospital, Groby 11 Road, Leicester LE3 9QP

12 d Department of Chemistry, University of Leicester, University Road, Leicester, LE1 7RH

13

14 KEYWORDS:

15 Volatile organic compounds, environmental VOC, indoor air pollution, breath analysis, TD16 GC-MS; thermal desorption-gas chromatography-mass spectrometry. 


\section{ABSTRACT}

19 The development of clinical breath-analysis is confounded by the variability of background 20 volatile organic compounds (VOC). Reliable interpretation of clinical breath-analysis at

21 individual, and cohort levels requires characterisation of clinical-VOC levels and exposures.

22 Active-sampling with thermal-desorption/gas chromatography-mass spectrometry recorded 23 and evaluated VOC concentrations in 245 samples of indoor air from three sites in a large 24 NHS provider trust in the UK over 27 months.

25 Data deconvolution, alignment and clustering isolated 7344 features attributable to VOC 26 and mapped the variability (composition and concentration) of respirable clinical VOC. 328 27 VOC were observed in more than $5 \%$ of the samples and 68 VOC appeared in more than $2830 \%$ of samples. Common VOC were associated with exogenous and endogenous sources and 17 VOC were identified as seasonal differentiators. The presence of metabolites from the anaesthetic sevoflurane, and putative-disease biomarkers in room air, indicated that

31 exhaled VOC were a source of background-pollution in clinical breath-testing activity.

32 With the exception of solvents, and PPE waxes, exhaled VOC concentrations above $3 \mu g \mathrm{~m}^{-3}$ 33 are unlikely to arise from room air contamination, and in the absence of extensive survey34 data, this level could be applied as a threshold for inclusion in studies, removing a potential 35 environmental confounding-factor in developing breath-based diagnostics. 


\section{INTRODUCTION}

38 Breathomics, is being developed to stratify patient phenotypes, and monitor metabolic and disease mechanisms ${ }^{1-3}$, and biomarker discovery with breathomics is being applied to conditions that include respiratory disease, cancer, infections and pulmonary illnesses ${ }^{4-6}$.

41 Further, breath analysis for assessing occupational exposure to VOC is well-established ${ }^{7-9}$.

42 A challenge in the development of clinical breath-testing is accounting for the heterogeneity

43 of patient responses to variable backgrounds of environmental VOC. Failure to adequately 44 address this factor may confound breathomic biomarker discovery and breath-testing 45 activity $10,11$.

46 Variability in breath biochemistry derives from: environmental contaminants; genetics; diet and lifestyle; diurnal changes in metabolism; endocrine cycles; medication; emotional/ psychological states; and, disease progression, see Figure 1. Environmental VOC exposure from inhalation, trans-dermal absorption or ingestion may result in elevated exhaled concentrations of VOC, and/or metabolic/catabolic products not originally in the

51 environment ${ }^{12}$. Further, endogenous VOC, and disease markers may also be obscured, 52 consequently, the VOC exposome generates a risk of false-attribution leading to breath53 testing outcomes that are difficult to reproduce or translate into clinical practice.

54 Studies of VOC in hospitals, homes, and workplace settings over a prolonged period have shown exhaled breath VOC and environmental VOC often contain the same VOC. Common VOC have been observed in matched samples from ventilators, blood, breath and the room-

57 air of clinics ${ }^{13,14}$. Widely reported VOC biomarkers for respiratory diseases, such as 58 cyclohexanone for COPD ${ }^{15}$ have also been detected in indoor air at concentrations $(1.13 \mu \mathrm{g}$ $\left.59 \mathrm{~m}^{-3}\right)^{16}$, close to those in exhaled breath $\left(0.4 \text { to } 10 \mu \mathrm{g} \mathrm{m}^{-3}\right)^{17}$. 


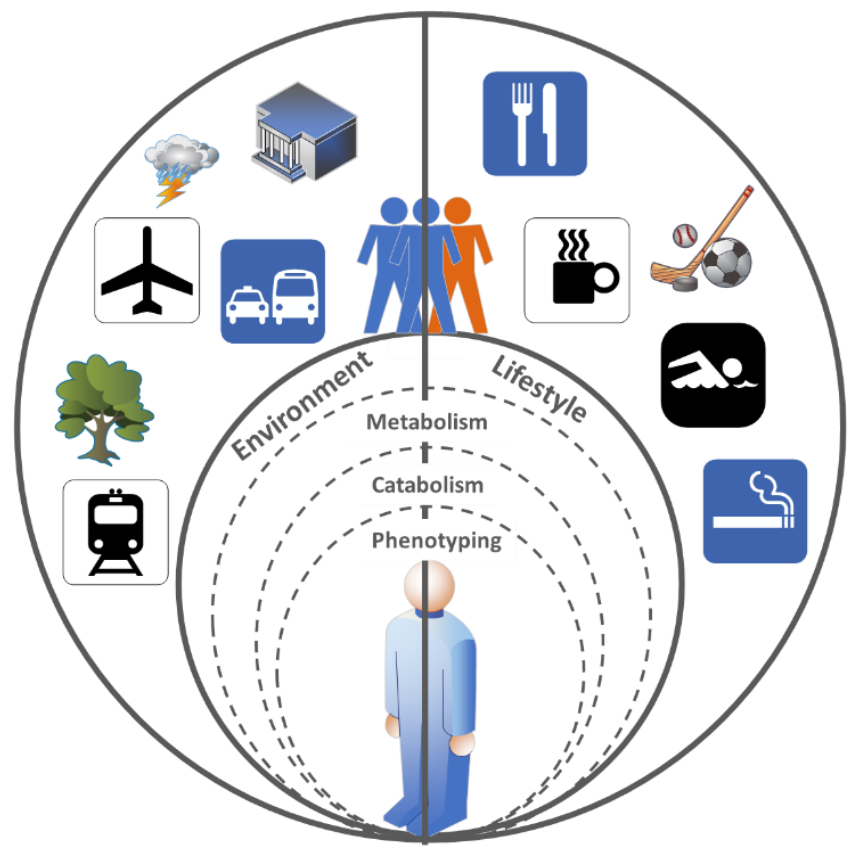

61 Figure 1 The observed exposome for each individual includes external factors such as

62

63

64

65

66

67 changes in the environmental background (acidity, basicity, ozone and humidity), and that environmental contamination and lifestyle, and also internal factors such as metabolism, catabolism and differences in phenotype. These are all factors in exhaled breath VOC.

Spatial and temporal variability of VOC in clinical settings has been observed with acetone, ethanol and propanol concentrations found to vary significantly while other VOC did not. Within the same study exhaled concentrations of acetone, ethanol, acetic acid, ammonia, isoprene and hydrogen cyanide were found to be higher in the breath of 10 clinical staff than in their surrounding environment, and propanol (a disinfectant) was at higher environmental concentrations ${ }^{18}$.

The sources and patterns of VOC in the indoor air of dwellings have been studied extensively with 2246 samples monitoring a panel of $61 \mathrm{VOC}$, enabling seasonal effects to be attributed to 8 proposed VOC patterns and sources ${ }^{16}$.

It is also helpful to note that the exogenous VOC toluene and benzene may also arise from degradation of the adsorbent Tenax TA (used in thermal desorption tubes), highlighting the point that analytical systems also create a trace VOC profile that may vary in response to Tenax and multibed thermal desorption sampling tubes should not be assumed to be inert ${ }^{19}$. 
79 Exogenous VOC may affect breath marker discovery by: raising exhaled breath 80 concentrations (false-positive); raising the concentration threshold for inclusion of an

81 exhaled VOC as coming from endogenous origin causing endogenous compounds to be

82 excluded from a study (false-negative); give rise to catabolite signals with endogenous

83 features (false-positive); and/or act as a contrast agent that leads to correct identification

84 of a process, mechanism, or breath-biochemical derangement, but in a non-reproducible 85 manner.

86 This study addressed the environmental VOC breathomics issue, and collected room-air 87 samples from three sites in a large NHS provider trust in the UK - University Hospitals of 88 Leicester. The aim was to characterise the variability of composition and concentration of 89 clinical-VOC, and establish, thresholds, or reference-levels, to inform occupational-exposure and breathomics workflows ${ }^{20}$. The resultant sample set captures real-world operational

91 clinical-VOC exposure across 27 months and reveals the variability and extent of exogenous 92 and endogenous VOC present in clinical room air at trace levels.

\section{MATERIALS AND METHODS}

94 This study and sampling campaign was part of a larger prospective, real-world, observational study, carried out in a tertiary cardio-respiratory centre in Leicester, United Kingdom, and . the study design, and methodology have been described in detail previously20.

97 Two hundred and forty five room-air samples were collected, of which 225 samples were collected from Respiratory Medicine and Clinical Decision Units at Glenfield Hospital, 99 Leicester, UK and 20 samples were collected from Paediatric Respiratory Medicine, 100 Leicester Royal Infirmary Hospital, Leicester, UK, from November 2016 to February 2019. 101 These samples were taken during normal clinical operations in the presence of patients participating in respiratory research, and research clinical staff. On occasions, other patients

103 and staff were present, particularly if the samples were collected from a ward-bay. 
104 VOC artefacts and contamination were reduced/eliminated from the materials and 105 components used within this study with appropriate combinations of solvent cleaning, 106 vacuum polishing, and temperature conditioning. All equipment was sealed in aluminium 107 packaging ready for use before shipping to the clinic. Research and clinical staff involved in 108 the study were trained to follow specifically designed sampling standard operating protocols, 109 and were proficiency tested in their use ${ }^{21}$. Sampling protocol checklists were used to verify 110 compliance with the standard operating protocols.

111 Indoor air was sampled $\left(1000 \mathrm{~cm}^{3}\right)$ using an Escort ELF pump (Part No. 497702, MSA), at 112 a flow rate of $500 \mathrm{~cm}^{3} \mathrm{~min}^{-1}$ for $120 \mathrm{~s}$ onto a Tenax $® /$ Carbotrap 1TD hydrophobic adsorbent 113 tube (Part No. C2-AXXX-5032, Markes International Ltd, Llantrisant, UK, see Figure S1). 114 Samples were sealed and immediately stored at ca. $4{ }^{\circ} \mathrm{C}$, before shipping to Loughborough 115 Centre for Analytical Science within approximately 3 days. Environmental samples were dry116 purged as soon as possible upon receipt with a $120 \mathrm{~cm}^{3}$ of purified nitrogen at a flow rate 117 of $60 \mathrm{~cm}^{3} \mathrm{~min}^{-1}$. Toluene-D8 (69 pg) and trichloromethane-d (280 pg) internal standards 118 were loaded during the dry purge onto the sample tube with a six-port valve attached to a 119 permeation tube-based test atmosphere generator (constructed in -house). Dry-purged and 120 internal-standard spiked samples were then sealed and stored at $4{ }^{\circ} \mathrm{C}$ prior to analysis.

121 TD-GC-MS operating conditions

122 Samples were analysed by thermal-desorption/gas-chromatography/mass-spectrometry 123 (TD/GC/qMS). A Unity-2 thermal desorption unit (Markes International, Cardiff, UK) was 124 interfaced to a GC (Agilent, 7890A) coupled to a quadrupole mass spectrometer (Agilent MS 125 5977A). The VOC collected during sampling were recovered and concentrated into a 126 hydrophobic cold trap yielding a 10,000-fold enrichment, the instrumentation parameters 127 are summarised in Table S1. 
129 Instrumentation performance was continuously monitored by analysing $0.2 \mu$ of a reference

130 mixture containing 20 standards (Table S2) daily before analysis. Instrument performance

131 was evaluated by monitoring the $Z$-scores of: retention time, peak area, height, width, and 132 symmetry for the 20 standards in the reference mixture. Analysis was undertaken when

133 instruments were within $Z= \pm 3$ for more than $80 \%$ of the 100 quality control parameters ${ }^{22}$.

134 The two internal standards were also monitored to track the combined stability of the TD-

135 GC-MS analysis and dry purging system.

136 Data processing

137 The TD-GC-MS data were deconvolved and an average of 120 VOC features per sample

138 (AnalyzerPro Spectral Works, UK) were extracted. The deconvolution method was optimised 139 to minimise over-deconvolution, (AnalyzerPro software method parameters were: minimum 140 peak area value, $=200, \mathrm{~S} / \mathrm{N}=3$, width of peak $=0.01$ and smoothing factor $=3$ ). The 141 extracted features were aligned using Kovats retention indexing (AnalyzerPro Spectral 142 Works, UK) ${ }^{23}$, and clustered using the vocCluster algorithm ${ }^{24}$ that assigned a unique 143 identifier in the form of (ERI- m/z1 - m/z2 - m/z3 - m/z4 - m/z5) to each VOC isolated and 144 grouped from the 245 samples; ERI indicated the retention index for the VOC environmental145 feature and $m / z 1 \ldots m / z_{n}$ were the nominal masses of the compound's ion fragments in 146 decreasing order of abundance needed to uniquely define the deconvolved VOC features 147 within the data-cube. The resultant sorted, and grouped features were consolidated into an 148 environmental-VOC-data matrix that contained the extracted peak areas for each of the 149 features isolated from each room-air sample.

150 Ubiquitous siloxanes arising from analytical artefacts were also removed from the 151 Environmental-VOC-Matrix, and 7 samples were discarded as they did not meet the quality 152 control measures. 
Multivariate analysis for seasonality effects

154 Once compounds that occurred in less than $30 \%$ of samples had been excluded, the matrix

155 features were $\log _{10}$ transformed and Pareto scaled before multivariate analysis was used to determine if there were any seasonal effects in the study ${ }^{25,26}$. The data was classified into

157 two groups; September-February, n=99 samples; and, March-August, $n=139$ samples.

158 Orthogonal partial least squares-discriminant analysis (OPLS-DA) was initially used to 159 identify seasonally invariant VOC, and these were removed from the analysis leaving 44 160 compounds for unsupervised principle components analysis (PCA). This approach followed 161 a multivariate statistical processing workflow using SIMCA-P+ software with integrated 7162 fold cross-validation to protect against overfitting (Version 16.1, Umetrics, UK) ${ }^{25}$.

163 Discriminating compounds were putatively assigned a Level-2 identification in accordance 164 with the Metabolomics Standards Initiative ${ }^{27}$, based on retention-index and NIST massspectral library matches.

\section{RESULTS}

167 Two hundred and forty five clinical room air samples yielded 7344 VOC features, with 328 compounds that occurred more than 12 times (5\%) that were selected for further assessment, see Figure 2. Sixty eight compounds appeared in more than $30 \%$ of the total samples. Thirty nine of these have been assigned a putative identity (Class 2 identification

171 level ${ }^{27}$ ) and a further 11 compounds were classified as hydrocarbons (Class 3 identification 172 level27), see Table 1. These data were used for multivariate analysis. (The identities of 173 eighteen of these compounds have yet to be elucidated.)

\section{Seasonality}

175 Seasonal variations in concentration, were identified from multi-variate analysis with 17 176 compounds found to be present at higher concentrations in samples obtained between 177 September and February, Figure S2 and Table S2. In 12 of the 17 compounds the 178 differences in concentration were statistically significantly different (normalised to the 179 internal standard). 


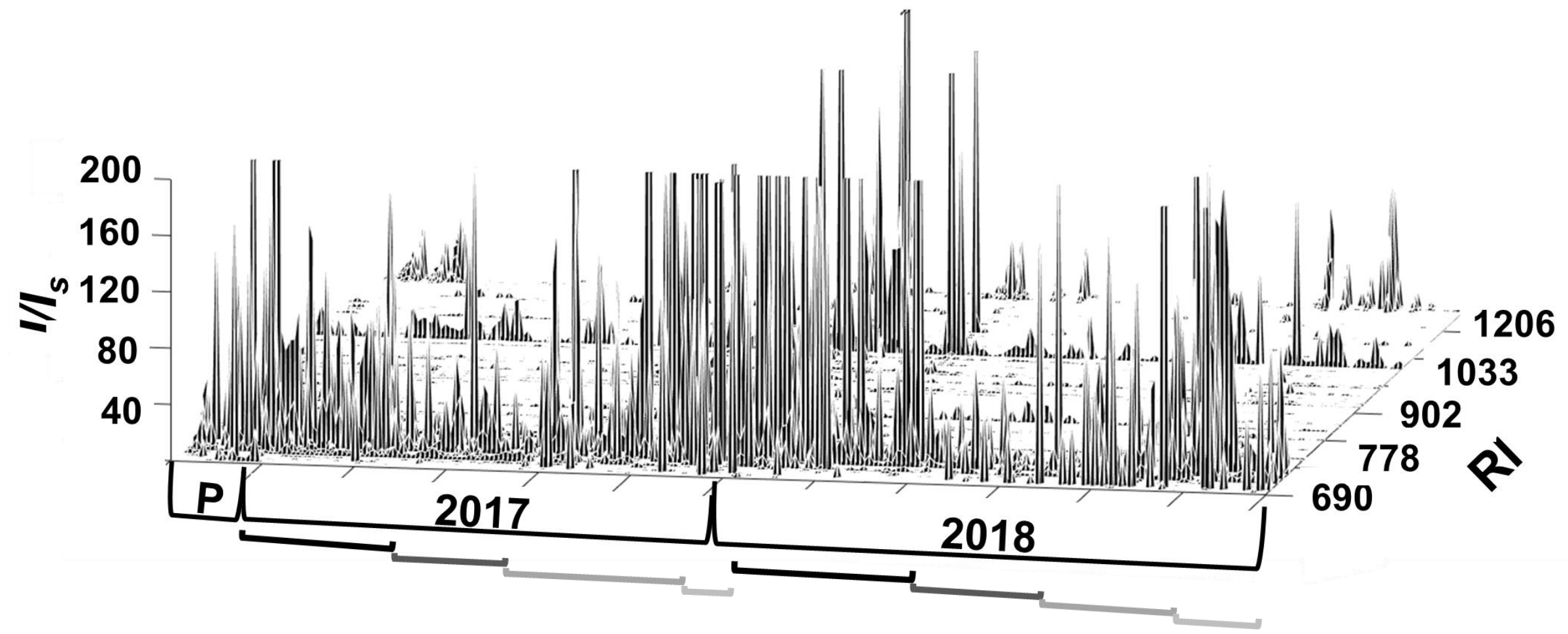

Figure 2: Common indoor VOC ( $>5 \%$ of samples) found in air samples from adult and the paediatrics clinics taken during November 2016 to February 2019. The VOC are plotted along the sampling timeline against their retention index (RI) values with their intensity normalised to $280 \mathrm{pg}$ of $\mathrm{C}\left({ }^{2} \mathrm{H}\right) \mathrm{Cl}_{3}$. $\mathrm{P}$ represents the data from the children's clinic. The rest of the data were obtained from the adults' wards with seasons of each year (spring, summer, autumn and winter) indicated by the grey shaded brackets found underneath each year. Note that 7016 VOC isolated from less than $5 \%$ of samples are not included. 
Table 150 VOC that have been putatively identified that appeared in more than $30 \%$ of the samples. ERI code (showing the retention index and quantifier $\mathrm{m} / \mathrm{z} 1$ and the qualifier ions $\mathrm{m} / \mathrm{z} 2-5)$, NIST-library matched identification, CAS number, mean intensity ratio to $\mathrm{C}\left({ }^{2} \mathrm{H}\right) \mathrm{Cl}^{3}$ internal standard $\left(\overline{\boldsymbol{I}} / \boldsymbol{I}_{\mathrm{IS}}\right)$, median intensity ratio to $\mathrm{C}\left({ }^{2} \mathrm{H}\right) \mathrm{Cl}_{3}$ internal standard $\left(\tilde{\boldsymbol{I}} / \boldsymbol{I}_{\mathrm{IS}}\right)$, standard deviation $(S)$ and frequency of observation $(F)$

\begin{tabular}{|c|c|c|c|c|c|c|c|}
\hline $\begin{array}{l}\text { VOC } \\
\text { no. }\end{array}$ & $\begin{array}{l}\text { ERI Code generated by } \\
\text { VOCCluster } 24\end{array}$ & Putative compound identification & CAS & $\overline{\boldsymbol{I}} / \boldsymbol{I}_{\mathrm{IS}}$ & $\tilde{\boldsymbol{I}} / \boldsymbol{I}_{\mathrm{IS}}$ & $\boldsymbol{S}$ & $\boldsymbol{F}$ \\
\hline 1 & ERI-670-101-151-103-85-153 & •1,1,2-trichloro-1,2,2-trifluoroethane- & $76-13-1$ & 0.64 & 0.72 & 0.32 & 91 \\
\hline 2 & ERI-683-45-46-43-42-44 & bethanol & $64-17-5$ & 21.9 & 11.37 & 39.72 & 234 \\
\hline$\overline{3}$ & ERI-685-45-43-58-42-0 & 2-propanol & $67-63-0$ & 104.1 & 38.95 & 218.3 & 169 \\
\hline 4 & ERI-688-67-53-68-51-50 & b•2-methyl-1,3-butadiene & $78-79-5$ & 0.64 & 0.44 & 0.84 & 144 \\
\hline 5 & ERI-700-43-45-60-42-41 & b ethanoic acid & $64-19-7$ & 2.77 & 1.72 & 3.41 & 184 \\
\hline 6 & ERI-712-78-77-51-50-52 & b benzene & $71-43-2$ & 1.76 & 1.44 & 2.68 & 220 \\
\hline 7 & ERI-778-91-92-65-63-51 & $\mathrm{b}$ toluene & $108-88-3$ & 1.71 & 0.97 & 2.71 & 204 \\
\hline 8 & ERI-787-41-86-45-68-68 & 2-methyl-2-propenoic acid, & $79-41-4$ & 0.42 & 0.33 & 0.26 & 80 \\
\hline 9 & ERI-791-50-46-66-66-82 & $\mathrm{N}$-containing compound & & 0.46 & 0.52 & 0.19 & 83 \\
\hline 10 & ERI-801-43-41-56-43-57 & b hexanal & $66-25-1$ & 0.40 & 0.29 & 0.30 & 157 \\
\hline 11 & ERI-814-43-56-41-73-61 & butyl ethanoate & $123-86-4$ & 0.50 & 0.38 & 0.48 & 113 \\
\hline 12 & ERI-854-43-72-57-42-58 & b 2-butanone & $78-93-3$ & 0.39 & 0.28 & 0.27 & 93 \\
\hline 13 & ERI-861-91-106-51-65-65 & b ethyl benzene & $100-41-4$ & 0.50 & 0.30 & 0.51 & 161 \\
\hline 14 & ERI-869-91-106-105-77-51 & b 1,4-dimethylbenzene & $106-42-3$ & 1.62 & 0.52 & 5.27 & 134 \\
\hline 15 & ERI-893-55-42-98-98-69 & b cyclohexanone & $108-94-1$ & 0.61 & 0.49 & 0.71 & 94 \\
\hline 16 & ERI-895-91-106-105-77-51 & b 1,2-dimethylbenzene, & $95-47-6$ & 0.64 & 0.40 & 1.50 & 170 \\
\hline 17 & ERI-907-57-45-41-87-56 & b2-butoxy-ethanol, & $111-76-2$ & 0.55 & 0.37 & 0.71 & 80 \\
\hline 18 & ERI-935-93-91-92-77-79 & (1R)-2,6,6-trimethylbicyclo[3.1.1]hept-2-ene & $7785-70-8$ & 0.57 & 0.47 & 0.51 & 157 \\
\hline 19 & ERI-960-77-105-106-51-50 & bbenzaldehyde & $100-52-7$ & 1.05 & 0.63 & 2.44 & 231 \\
\hline 20 & ERI-983-94-66-65-63-55 & bphenol & $13127-88-3$ & 1.09 & 0.64 & 2.86 & 228 \\
\hline 21 & ERI-985-103-76-50-75-75 & •trans-cinnamic acid ((2E)-3-Phenyl-2-propenoate) & $140-10-3$ & 0.37 & 0.25 & 0.31 & 144 \\
\hline 22 & ERI-987-43-41-55-69-108 & b.6-methyl-5-hepten-2-one, & $110-93-0$ & 0.48 & 0.39 & 0.37 & 195 \\
\hline 23 & ERI-995-105-120-91-103-51 & b1-methylethylbenzene & $98-82-8$ & 0.50 & 0.34 & 0.97 & 80 \\
\hline 24 & ERI-997-105-120-77-91-119 & b1,2,3-trimethylbenzene, & $526-73-8$ & 0.54 & 0.49 & 0.42 & 77 \\
\hline 25 & ERI-1003-41-43-57-56-0 & boctanal & $124-13-0$ & 0.39 & 0.29 & 0.27 & 110 \\
\hline 26 & ERI-1026-119-134-134-117-77 & 1-methyl-4-(1-methylethyl) benzene & $99-87-6$ & 0.52 & 0.36 & 0.60 & 101 \\
\hline 27 & ERI-1029-57-41-43-55-56 & b2-ethyl 1-hexanol- & $104-76-7$ & 1.21 & 0.68 & 1.86 & 222 \\
\hline 28 & ERI-1030-68-67-93-79-53 & b1-Methyl-4-methylethenylcyclohexene & $138-86-3$ & 2.15 & 0.57 & 13.46 & 212 \\
\hline 29 & ERI-1035-79-108-77-107-51 & bphenylmethanol & $100-51-6$ & 0.46 & 0.38 & 0.31 & 100 \\
\hline 30 & ERI-1068-105-77-51-120-50 & b1-phenylethanone & $98-86-2$ & 0.50 & 0.34 & 0.46 & 172 \\
\hline 31 & ERI-1073-59-43-55-41-67 & 2,6-dimethyl -7-octen-2-ol & $18479-58-8$ & 0.76 & 0.38 & 1.80 & 111 \\
\hline
\end{tabular}




\begin{tabular}{|c|c|c|c|c|c|c|c|}
\hline 32 & ERI-1104-57-41-43-55-56 & bnonanal & $124-19-6$ & 0.79 & 0.64 & 0.69 & 215 \\
\hline 33 & ERI-1145-55-41-97-70-57 & •6-methyl-1-octanol & $110453-78-6$ & 0.46 & 0.38 & 0.43 & 84 \\
\hline 34 & ERI-1169-105-77-122-51-50 & N-containing compound & $\mathrm{N} / \mathrm{A}$ & 0.39 & 0.31 & 0.27 & 82 \\
\hline 35 & ERI-1176-71-81-95-41-55 & (1R,2R,5R)-2-Isopropyl-5-methylcyclohexanol & $491-02-1$ & 0.95 & 0.45 & 3.32 & 89 \\
\hline 36 & ERI-1206-41-43-57-55-44 & bdecanal & $112-31-2$ & 0.43 & 0.32 & 0.32 & 155 \\
\hline 37 & ERI-1377-71-43-56-89-41 & 3-hydroxy-2,4,4-trimethylpentyl 2-methylpropanoate & $74367-34-3$ & 0.59 & 0.33 & 0.93 & 92 \\
\hline 38 & ERI-1606-71-43-41-56-55 & $\begin{array}{l}\text { 2,4,4-trimethyl-1,3-pentanediyl bis (2-methyl } \\
\text { propanoate) }\end{array}$ & $74381-40-1$ & 2.02 & 0.53 & 3.25 & 112 \\
\hline 39 & ERI-2333-102-260-232-231-76 & 2,5-diphenyl-2,5-cyclohexadiene-1,4-dione,- & $844-51-9$ & 3.10 & 0.58 & 8.77 & 74 \\
\hline 40 & ERI-679-44-43-41-42-56 & & & 6.75 & 2.55 & 21.55 & 219 \\
\hline 41 & ERI-690-43-57-41-56-42 & & & 0.76 & 0.41 & 1.41 & 119 \\
\hline 42 & ERI-722-43-57-56-58-86 & & & 0.42 & 0.32 & 0.26 & 98 \\
\hline 43 & ERI-991-57-56-41-43-55 & & & 0.72 & 0.39 & 1.39 & 161 \\
\hline 44 & ERI-1000-43-57-41-71-85 & & & 0.61 & 0.34 & 2.21 & 173 \\
\hline 45 & ERI-1100-57-43-41-71-55 & hydrocarbon & & 0.65 & 0.40 & 1.67 & 86 \\
\hline 46 & ERI-1200-57-43-41-71-85 & & & 0.42 & 0.30 & 0.37 & 192 \\
\hline 47 & ERI-1303-57-43-41-67-85 & & & 0.46 & 0.38 & 0.35 & 86 \\
\hline 48 & ERI-1400-57-43-71-41-85 & & & 0.45 & 0.34 & 0.38 & 159 \\
\hline 49 & ERI-1605-57-43-71-41-85 & & & 0.62 & 0.40 & 0.85 & 96 \\
\hline 50 & ERI-2342-57-43-71-85-41 & & & 14.58 & 0.94 & 64.72 & 74 \\
\hline
\end{tabular}


194 Cyclohexanone $(1.5$-fold increase, $t$ - statistic $=1.79$, one-tailed critical t-value $=1.66, p=$ 1950.038 with 62 degrees of freedom) has been previously reported as a marker for COPD 196 (sensitivity $=60 \%$ and specificity $=91 \%)^{28}$. Benzaldehyde $(2.2$-fold increase t-statistic $=$ 1972.27 , one-tailed critical t-value $=1.66, p=0.012$ with 100 degrees of freedom) is involved in 198 fatty-acid and tryptophan metabolism as well as glycolysis/gluconeogenesis ${ }^{29}$. Exhaled 199 benzaldehyde has also been reported: in breath samples from participants with severe pulmonary arterial hypertension, as well as healthy individuals ${ }^{30}$; possibly generated from 201 bacterial degradation of common amino acids such as phenylalanine, tryptophan or 202 tyrosine ${ }^{30}$; lung cancer cell lines $(n=6)$ discriminating from healthy control cell lines $(n=1)$ 31; and, has also been proposed to originate from exposure to tobacco smoke, radiation or air pollution with peroxidative properties capable of damaging enzymes and DNA ${ }^{32}$. Phenol (2.1-fold increase, t-value statistic $=1.84$, one-tailed critical t-value $=1.66, p=0.034$ with 95 degrees of freedom.) is associated with petroleum products as well as tobacco smoke 33 . Phenol is also associated with oesophageal or gastric adenocarcinoma, and has been observed to be significantly higher in cancer patients $(n=81)$ compared to healthy individuals $(n=129)(P<0.05)^{34}$, Figure 3.

Ethanol (2-fold increase, $t$ - statistic $=2.63$, one-tailed critical t-value $=1.66, p=0.0048$ with

211113 degrees of freedom) and ethanal (2-fold increase but not statistically significant) may 212 be attributed to ethanol consumption and metabolism with the observed increases in 213 abundances of due to higher seasonal alcohol consumption. (Note that the ethanal mass 214 spectrum did not fall completely in the mass spectrometric scan range and verification with derivatisation was not undertaken.)

216 Cleaning product/disinfectants such as 2-propanol (2-fold increase, $t$ - statistic $=2.18$, one217 tailed critical t-value $=1.66, p=0.016$ with 85 degrees of freedom) were also higher in 218 winter 
219 Variation between different clinical settings was discernible with 3 compounds unique to the

220 paediatric setting that were related to the paediatric anaesthetic sevoflurane 35,36 .

221 Sevoflurane and its two metabolites 1,1,1,3,3,3-hexafluoro-2-propanone, and 1,1,1,3,3,3-

222 hexafluoro-2-propanol were putatively identified based on NIST-mass-spectral library

223 matches, see Figure S3. Sevoflurane and its metabolite 2-propanol, 1,1,1,3,3,3-hexafluoro

224 have been measured previously in human breath $(n=6)$, and used to build a three-

225 compartment pharmacokinetics model to study environmental contaminants and breath

226 data ${ }^{37}$, The presence of these VOC may well have arisen from a ventilation circuit shared

227 with a surgical theatre on a different floor of the building.
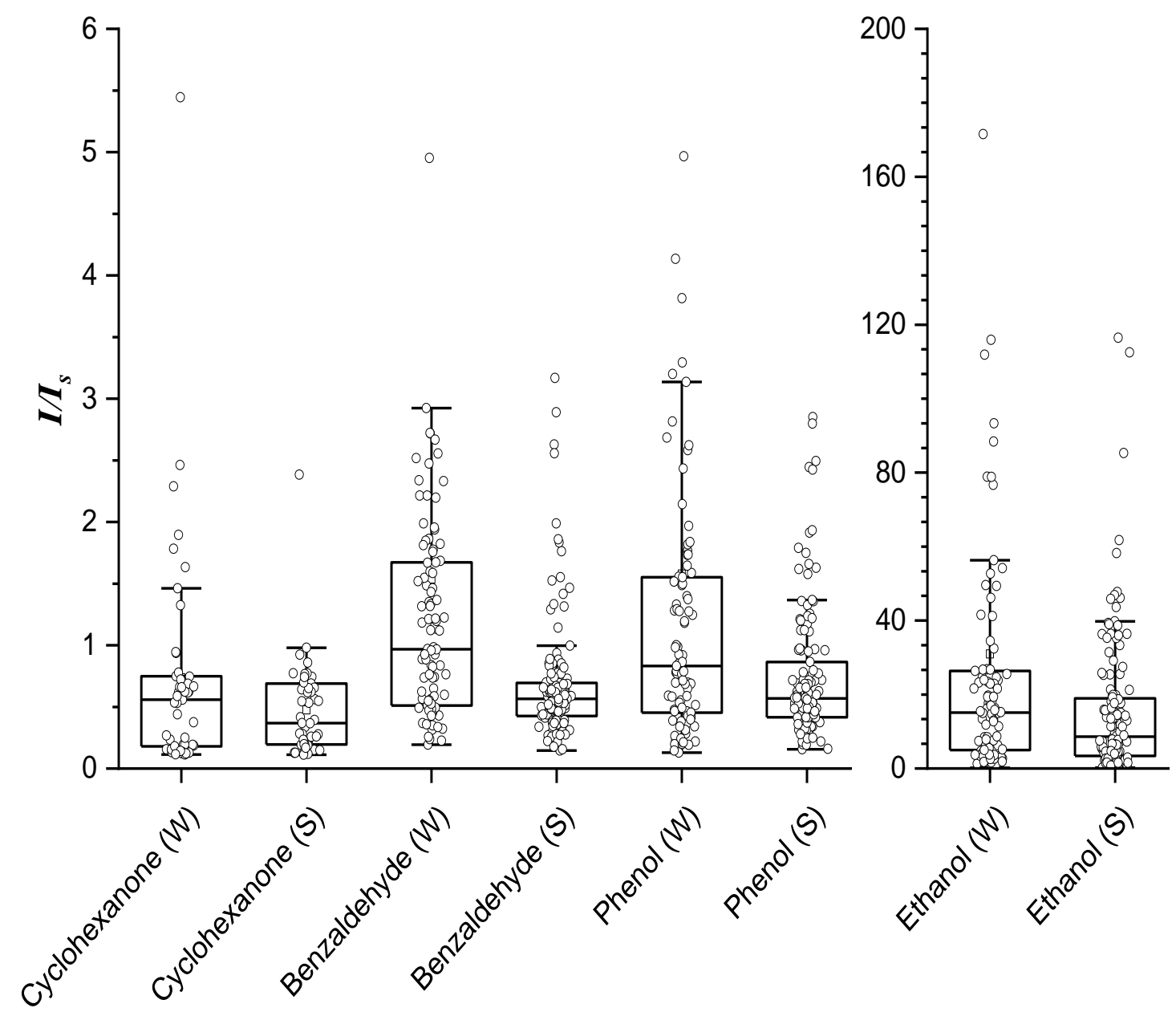

Figure 3 Box whisker plots for cyclohexanone, benzaldehyde, phenol, and ethanol contrasting the differences in profiles between Winter (W), September-February, $\mathrm{n}=99$ samples and Summer (s), March-August, $\mathrm{n}=139$ samples. Note that winter outliers for benzaldehyde and phenol with $I / I_{S}$ values of 36.6 and 42.6 
respectively are not shown. $I / I_{S}$ denotes signal intensity relative to the internal standard $\mathrm{C}\left({ }^{2} \mathrm{H}\right) \mathrm{Cl}_{3}$ signal.

235 As well as cyclohexanone and benzaldehyde other disease markers were found in the room nonanal, hexanal and decanal across the sampling campaign.

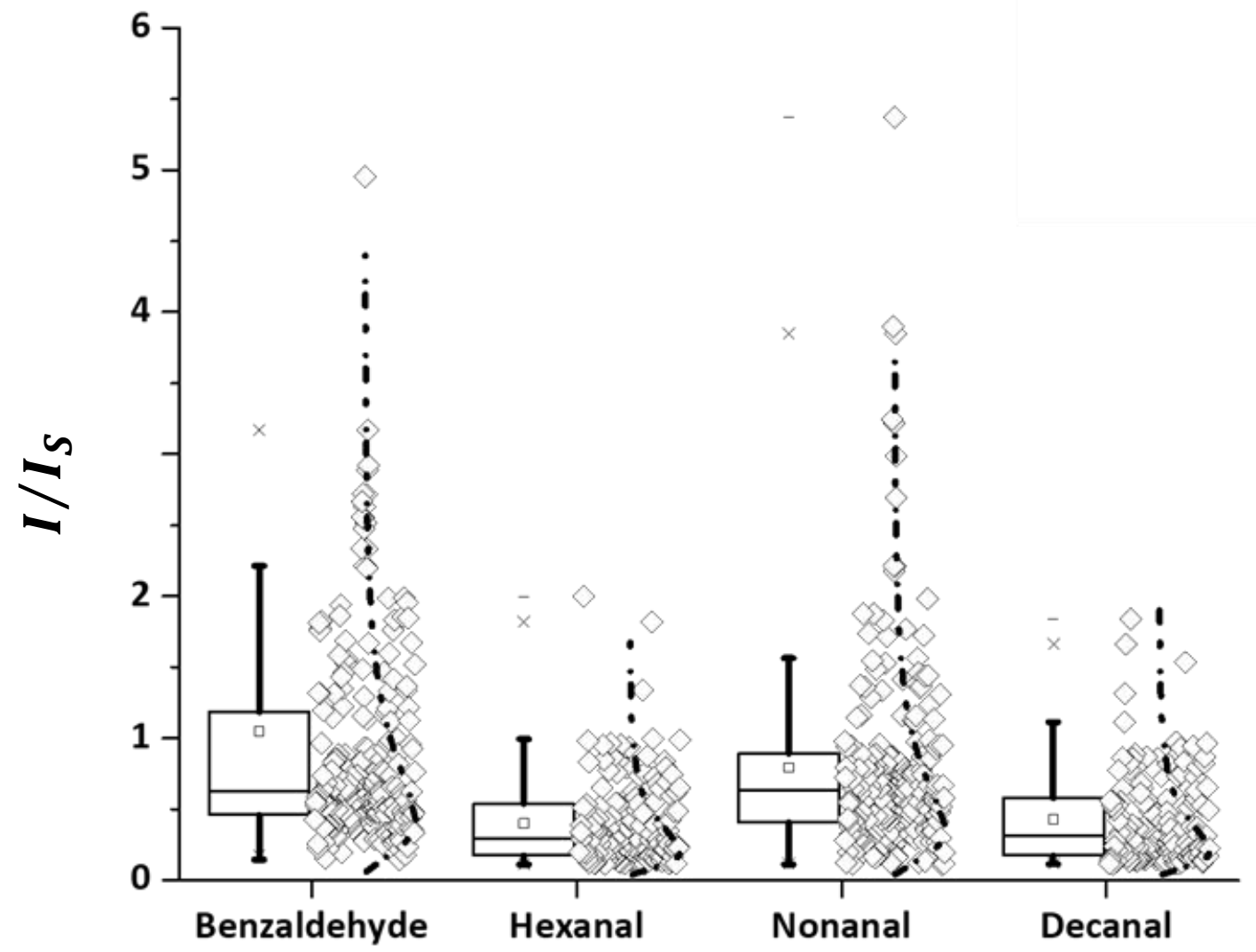

Figure 4 Box plots and lognormal distribution curves for benzaldehyde, hexanal, nonanal and 2-propanol, decanal, showing the prevalence of these often-reported breath biomarkers in clinical room air samples.

242 Another commonly reported breath biomarker, octanal, was also present, and provides a

243 useful case-study into the variability of the concentrations encountered and the frequency

244 of occurrence. Octanal was isolated from 101 environmental samples, a frequency of 245 occurrence of $42 \%$, the highest concentration observed was estimated to be $96 \mathrm{ng} \mathrm{m}^{-3}$ 246 (expressed as a $\left.\mathrm{C}^{2} \mathrm{H}\right) \mathrm{Cl}_{3}$ equivalent) with a minimum observed concentration of $1.04 \mathrm{ng} \mathrm{m}$ $247{ }^{3}$, and the median observed octanal concentration was $24.32 \mathrm{ng} \mathrm{m}^{-3}$. Tests for normality and log-normality (Shapiro-Wilk) indicated a non-normal distribution and assessment of the time 
250 to all of the 328 most frequently observed VOC revealed that most were present at

251 concentrations below a threshold of $3 \mu \mathrm{g} \mathrm{m} \mathrm{m}^{-3}$ (expressed as a $\mathrm{C}\left({ }^{2} \mathrm{H}\right) \mathrm{Cl}_{3}$ equivalent) with 14

252 compounds present at higher concentrations in the range 10 to $100 \mu \mathrm{g} \mathrm{m}^{-3}$, see Figure 6.

253 The compounds present at the highest concentrations appear to be associated with solvent

254 and disinfection formulations (2-propanol for example), or, higher molecular weight waxes

255 associated with the use of nitrile protective gloves. The more volatile the contaminant the

256 more frequently it was observed.
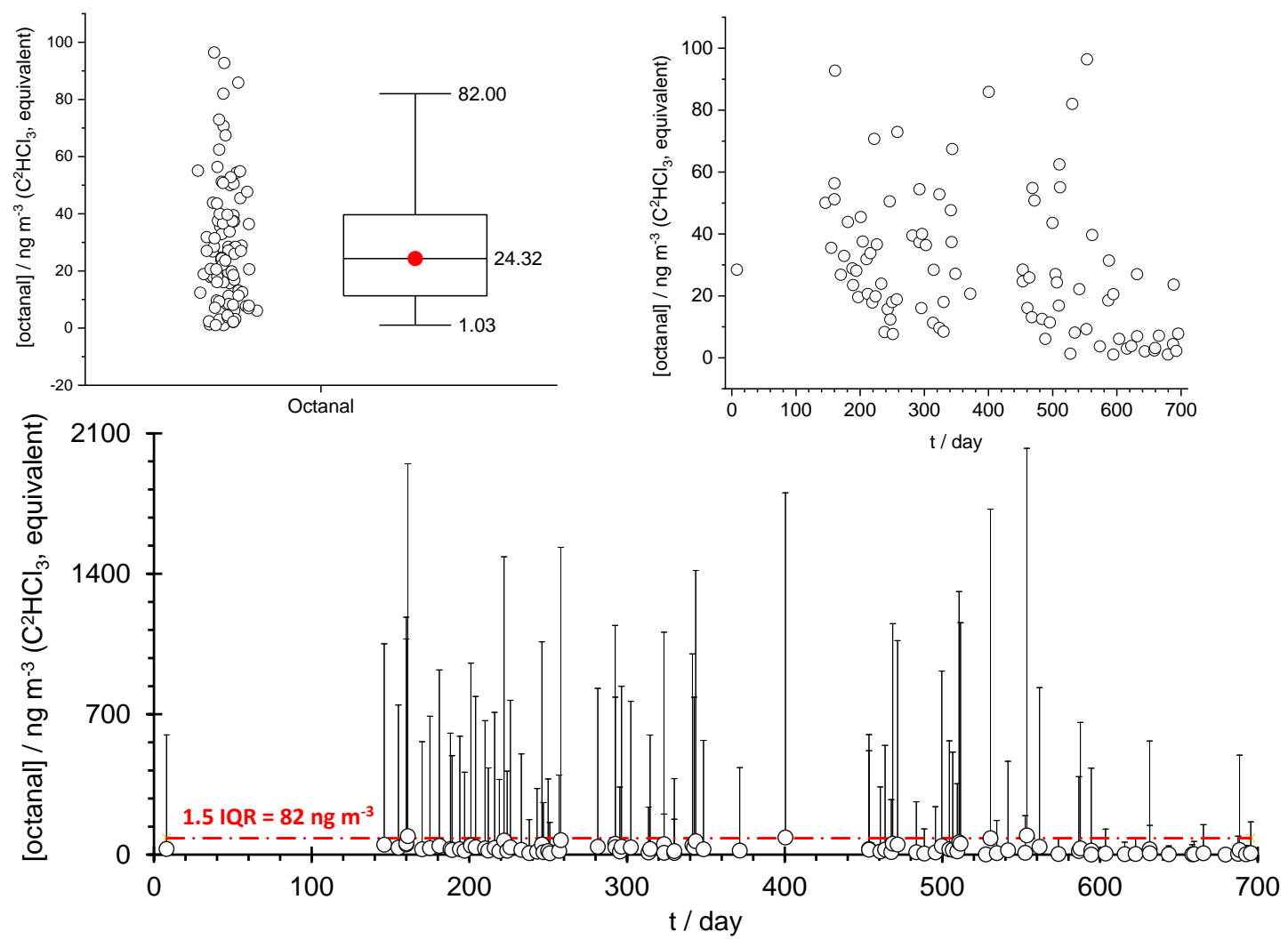

Figure 5 A summary of the environmental concentrations of octanal observed over the study. Top left, the distribution of octanal concentration; top right, the time series concentration data of background octanal concentration; and, bottom the octanal levels indicated by circles with the dashed line showing the upper limit from the distribution in the top left figure. The bottom figure's whiskers indicate the 20-fold threshold widely applied for the inclusion/exclusion threshold for admitting a VOC into a breath biomarker discovery and validation data set. The non-reproducibility and variability of such an approach may be discerned. 


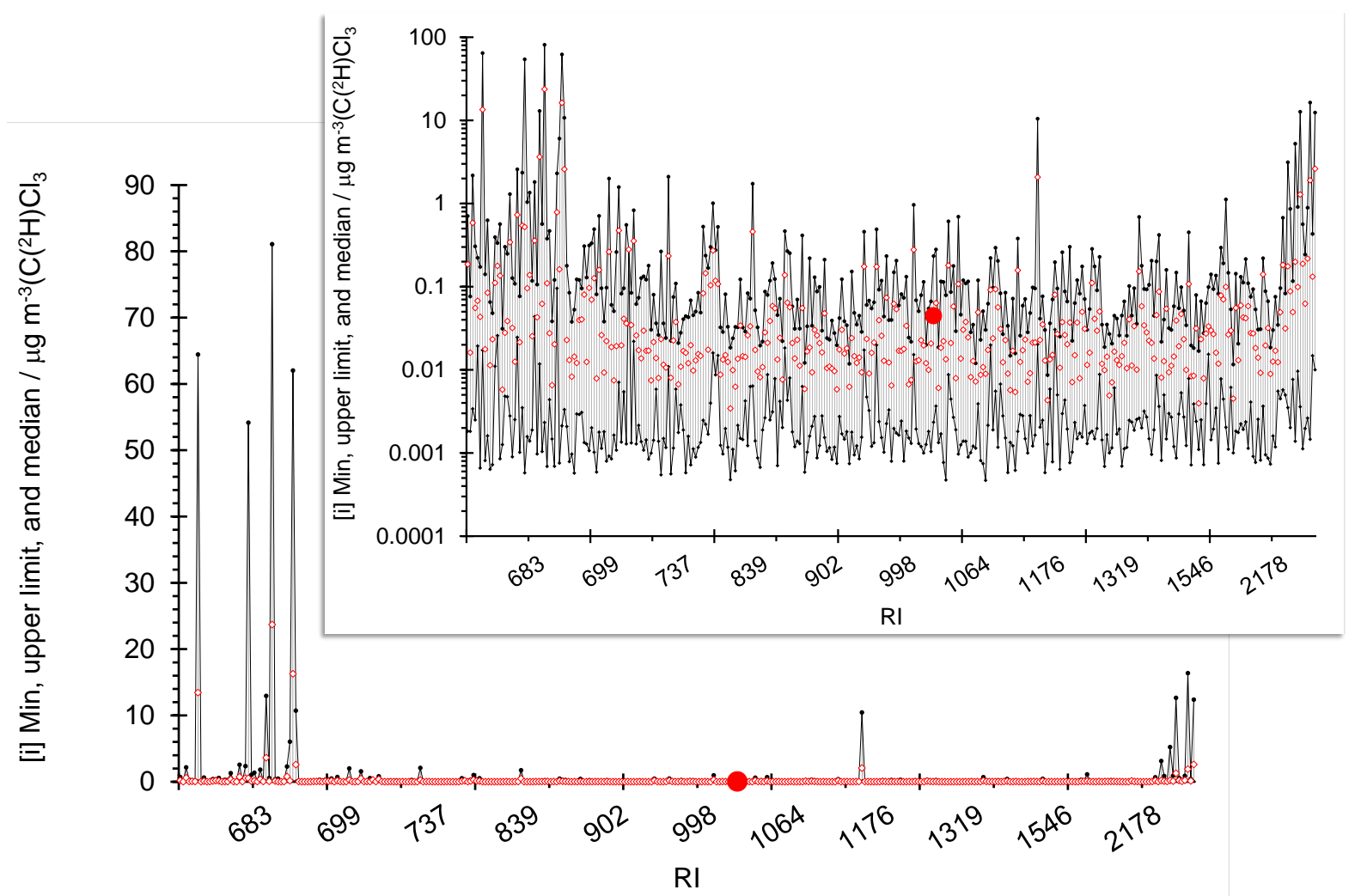

Figure 6 The minimum, median (red diamonds) and upper limit of observed concentrations across the 328 most frequently observed (> 5\% ) VOC over the duration of the study. The octanal entry is denoted by the solid red circle. The concentrations of these compounds spanned a range of 2 to 3 orders of magnitude and were typically below $3 \mu \mathrm{g} \mathrm{m}{ }^{-3}$ (expressed as a $\mathrm{C}\left({ }^{2} \mathrm{H}\right) \mathrm{Cl}_{3}$ equivalent) with the exception of volatile solvents (RI less than 690) and heavier waxes associated with PPE production (RI greater than 2180). DISCUSSION

276 This study describes the complexity of the contamination profiles and concentration

277 distributions of $\mathrm{VOC}$ in the indoor air of hospitals and highlights seasonal and clinical

278 variations. Ninety five percent of the compounds observed occurred in in less than $5 \%$ of 279 samples, creating a highly variable and non-reproducible VOC profile. Such variability may 280 be attributed to the constantly changing demographic of the occupants of a busy clinical 281 facility, combined with the range of therapies and therapeutics being administered. A less 282 variable constituency of the background contained a mixture of ubiquitous exogenous VOC. 283 Further, evidence that exhaled VOC may also be considered as VOC source in a clinical 284 environment, and that seasonal factors were also present, was noted. 
286 Changes in the VOC composition of room air from exhaled breath have been described with on-line proton transfer mass spectrometric studies reporting the presence of low molecular weight exhaled VOC, with estimated exemplar office air concentrations for acetone, ethanol, and isoprene of 52, 32, and $13 \mu \mathrm{g} \mathrm{m} \mathrm{m}^{-3}$ respectively ${ }^{38}$, while studies with cinema audiences have monitored, and coded, VOC levels in room air to the emotional states of the scenes

291 being viewed ${ }^{39}$. Other VOC associated with skin volatiles and the gastric tract were also

292 reported as constituents of the cinema auditorium's air. At a significantly larger scale, 293 changes in VOC levels in stadium air have been reported at sports events with isoprene, 294 acetone and ethanol increasing to $8.5,9.7$ and $580 \mu \mathrm{g} \mathrm{m} \mathrm{m}^{-3}$ respectively during a football 295 match $^{40}$. Such studies suggested that the observation of exhaled volatiles in clinical room air was to be anticipated, and that the $10^{4}$ sample enrichment obtained through two stage thermal desorption, combined with temperature programming, would enable concentrations lower than $1 \mu g \mathrm{~m}^{-3}$ to be monitored.

299 Exhaled VOC at trace levels were found in the room air of the clinics studied, most notably 300 the two metabolites of sevoflurane, for it is difficult to conceive of an alternative source. The 301 aldehydes in Figure 4, noted as oxidative stress biomarkers associated with respiratory disease, have also been associated with aging and outgassing from linoleum flooring ${ }^{16}$, and decanal is also an oxidative product of skin lipids. It seems plausible to propose that the observed airborne concentrations of aldehydes were derived from a combination of constant background emissions due to outgassing from flooring and building materials, overlaid with concentration transients from exhaled breath combined with changes in room occupancy

307 and associated ventilation.

308 Seasonal VOC.

309 Previous studies on VOC domestic air contaminants ${ }^{16}$ have considered seasonal factors in 310 indoor contamination profiles and levels. Factors such as seasonal changes in ventilation 
311 and indoor-based activities were identified. Further, the effect of solar-radiation on building

312 materials and outgassing was highlighted. The VOC in Table S2 that differentiate between

313 the summer and winter months may be attributed to sources that include: cleaning and 314 disinfection materials (propan-2-ol, (1R,2S,5R)-2-isopropyl-5-methylcyclohexanol 315 [dimenthol], (6S)-2,6-Dimethyl-7-octen-2-ol, (6S)-2,6-Dimethyl-7-octen-2-ol and 2316 butoxyethanol); outgassing from plasticiser/polymer components (2-ethyl-1-hexanol and 317 2,5-Cyclohexadiene-1,4-dione-2,5-diphenyl, phenol, 1-methylethylbenzene 318 [isopropylbenzene] and cyclohexanone); pollutants associated with fugitive emissions from 319 vehicles and their exhausts (toluene, ethylbenzene, benzene, 1,4-dimethylbenzene and 1,2320 dimethylbenzene, 1-methylethylbenzene); and exhaled volatiles (cyclohexanone, ethanol 321 and ethanal). Such seasonal changes are consistent with changes in ventilation, noted 322 previously16, and increased usage of cleaning products associated with higher bed 323 occupancy rates during the winter season. Increased concentrations of ethanol and its 324 catabolite, ethanal are consistent with winter patterns of alcohol consumption, combined 325 with changes in ventilation.

326 Breath-biochemistry research and biomarker discovery and monitoring studies manage 327 room air contamination compounds in different ways. Some studies invoke an "alveolar 328 gradient" concept ${ }^{41}$ and others remove compounds from the data-processing workflow 329 where the environmental background is greater or equal to $5 \%$ of the exhaled concentration. 330 An alveolar gradient approach is problematic because: the data presented in this paper 331 indicate that important disease markers are routinely also present in room air; and in a 332 clinical environment a participant's exposure to a specific VOC is unknown, as is the 333 subsequent rate of the compound's elimination prior to the breath sample being taken. 334 Another approach that excludes breath data if it is detected in the environment ${ }^{42}$ is also unsatisfactory for the first reason given above. 
336 Alveolar gradient and environmental exclusion approaches are unlikely to resolve the 337 confounding factor of variable environmental backgrounds, participant exposures, and 338 participants' catabolisms. Further, such approaches also create the possibility of 339 uncontrolled, and variable, site and time dependent factors determining whether or not 340 participant data is admitted into a study. Figure 5 shows a range of inclusion concentrations 341 (20 times the environmental background that might be applied over the 245 breath data 342 sets acquired) for octanal with a range from ca. $20 \mathrm{ng} \mathrm{m}^{-3}$ to $2 \mu \mathrm{g} \mathrm{m} \mathrm{m}^{-3}$ (expressed as a $343 \mathrm{C}\left({ }^{2} \mathrm{H}\right) \mathrm{Cl}_{3}$ equivalent). Adopting a concentration gradient approach means that the inclusion 344 criteria for breath data varies between participants in an apparently arbitrary manner with 345 little or no evidence to relate the studies threshold concentration (for that particular sample) 346 to exposure or washout.

347 With the exception of a few solvents (formulation compounds) and some mould release 348 agents, associated with disposable PPE, most volatiles, when present, were below a 349 threshold, see Figure 6. In the case of octanal this was $82 \mathrm{ng} \mathrm{m}^{-3}$ (expressed as a $\mathrm{C}\left({ }^{2} \mathrm{H}\right) \mathrm{Cl}_{3}$ 350 equivalent), and an exhaled breath concentration above this level was highly unlikely to be 351 due to environmental exposure. A study of the 328 common pollutants indicates that a 352 default level of $3 \mu \mathrm{g} \mathrm{m} \mathrm{m}^{-3}$ (expressed as a $\mathrm{C}\left({ }^{2} \mathrm{H}\right) \mathrm{Cl}_{3}$ equivalent) is a threshold concentration 353 above which most clinical room air VOC do not rise. In the absence of reliable site-specific 354 environmental survey data applying such a threshold is a more reliable, reproducible and 355 systematic approach than adopting the variable levels acquired by spot sampling. Infrequent 356 VOC contamination transients would be identified as outliers and rare events in the exhaled 357 breath profiles and be excluded from the data pipeline in the event they occurred.

358 Seasonal factors mean that studies and clinical breath testing need to account for possible 359 bias. More robust discovery designs will randomise recruitment of participants over the 360 seasons of the year and avoid overweighting those months with higher occupancy and 
361 higher clinical VOC levels. Such attention to scheduling might also be usefully applied to sampling sessions in clinic to identify other possible synchronisation of environmental exposure with sampling activities; cleaning, cooking and medication for example.

VOC that are frequently present within a facility at elevated concentrations may introduce a "contrast agent" into breath studies, in that differentiation between classes of participants may be based on differences in how the contaminant is metabolised, arising from catabolic changes due to disease or treatment. Such a situation may result in fortuitous discovery, or non-reproducible results. It will be helpful to note and report background contaminants routinely detected at elevated concentration (i.e., above $3 \mu \mathrm{g} \mathrm{m}^{-3}$ ) and whether they may be modelled as part of breath data or not.

371 Finally, adopting a concentration threshold approach does not remove the necessity for obtaining reliable environmental background data as part of breath testing operations, such samples and analysis should still an integral part of a quality assurance and control protocol.

\section{ACKNOWLEDGMENTS}

375 This research was funded by the Medical Research Council (MRC), Engineering and Physical 376 Sciences Research Council (EPSRC) Stratified Medicine Grant for Molecular Pathology 377 Nodes (Grant No. MR/N005880/1), Midlands Asthma and Allergy Research Association 378 (MAARA) And British Lung Foundation (Grant No. BLFPHD17-1). The work was carried out at 379 the University Hospitals of Leicester NHS Trust, University of Leicester and Loughborough 380 University, supported by the NIHR Leicester Biomedical Research Centre and the NIHR

381 Leicester Clinical Research Facility. The views expressed are those of the author(s) and not necessarily those of the NHS, the NIHR or the Department of Health and Social Care. The authors would like to acknowledge the invaluable efforts of the research nurses responsible 
Breathomics Pathology Node consortium (members list can be found at:

https://ember.le.ac.uk/web).

The authors would like to thank Spectralworks for support with data processing and their

AnalyzerPro software that we used for data deconvolution and alignment.

Ethics approval. The study obtained full ethical approval from the London South East

Research ethics Committee, REC reference 16/LO/1747.

391

392

393

394

395

396

397

398

399

400

401

402

403

404

405

406

407

408

409

410

411

412

413

414

415

416

417

418

419

\section{REFERENCES}

(1) Lourenço, C.; Turner, C. Breath Analysis in Disease Diagnosis: Methodological Considerations and Applications. Metabolites 2014, 4 (2), 465-498. https://doi.org/10.3390/metabo4020465.

(2) Wheelock, C. E.; Goss, V. M.; Balgoma, D.; Nicholas, B.; Brandsma, J.; Skipp, P. J.; Snowden, S.; Burg, D.; D’Amico, A.; Horvath, I.; Chaiboonchoe, A.; Ahmed, H.; Ballereau, S.; Rossios, C.; Chung, K. F.; Montuschi, P.; Fowler, S. J.; Adcock, I. M.; Postle, A. D.; Dahlén, S.-E.; Rowe, A.; Sterk, P. J.; Auffray, C.; Djukanović, R.; Group, the U.-B. S. Application of 'omics Technologies to Biomarker Discovery in Inflammatory Lung Diseases. Eur. Respir. J. 2013, 42 (3), 802-825. https://doi.org/10.1183/09031936.00078812.

(3) Breathborne Biomarkers and the Human Volatilome, 2nd ed.; Jonathan Beauchamp; Cristina Davis; Joachim Pleil, Ed.; Elsevier B.V., 2020. https://doi.org/10.1016/c2018-0-04980-4.

(4) Pereira, J.; Porto-Figueira, P.; Cavaco, C.; Taunk, K.; Rapole, S.; Dhakne, R.; Nagarajaram, H.; Câmara, J. S. Breath Analysis as a Potential and Non-Invasive Frontier in Disease Diagnosis: An Overview. Metabolites 2015, 5 (1), 3-55. https://doi.org/10.3390/metabo5010003.

(5) Boots, A. W.; van Berkel, J. J. B. N.; Dallinga, J. W.; Smolinska, A.; Wouters, E. F.; van Schooten, F. J. The Versatile Use of Exhaled Volatile Organic Compounds in Human Health and Disease. J. Breath Res. 2012, 6 (2), 027108. https://doi.org/10.1088/1752-7155/6/2/027108.

(6) Boots, A. W.; Bos, L. D.; van der Schee, M. P.; van Schooten, F.-J.; Sterk, P. J. Exhaled Molecular Fingerprinting in Diagnosis and Monitoring: Validating Volatile Promises. Trends Mol. Med. 2015, 21 (10), 633-644. https://doi.org/10.1016/j.molmed.2015.08.001.

(7) Amorim, L. C. A.; de L. Cardeal, Z. Breath Air Analysis and Its Use as a Biomarker in Biological Monitoring of Occupational and Environmental Exposure to Chemical Agents. Journal of Chromatography B: Analytical Technologies in the Biomedical and 
Life Sciences. Elsevier June 15, 2007, pp 1-9.

https://doi.org/10.1016/j.jchromb.2007.03.023.

422

423

424

425

426

427

428

429

430

431

432

433

434

435

436

437

438

439

440

441

442

443

444

445

446

447

448

449

450

451

452

453

454

455

456

457

(8) Droz, P. O.; Guillemin, M. P. Occupational Exposure Monitoring Using Breath Analysis. J. Occup. Med. 1986, 28 (8), 593-602. https://doi.org/10.1097/00043764198608000-00014.

(9) Sanchez, J. M. Air and Breath Analysis for the Assessment of Exposure to Solvent Emissions in University Chemistry Laboratories. Atmos. Pollut. Res. 2019, 10 (6), 1795-1802. https://doi.org/10.1016/j.apr.2019.07.011.

(10) Pleil, J. D.; Stiegel, M. A.; Risby, T. H. Clinical Breath Analysis: Discriminating between Human Endogenous Compounds and Exogenous (Environmental) Chemical Confounders. J. Breath Res. 2013, 7 (1), 017107. https://doi.org/10.1088/17527155/7/1/017107.

(11) Blanchet, L.; Smolinska, A.; Baranska, A.; Tigchelaar, E.; Swertz, M.; Zhernakova, A.; Dallinga, J. W.; Wijmenga, C.; van Schooten, F. J. Factors That Influence the Volatile Organic Compound Content in Human Breath. J. Breath Res. 2017, 11 (1), 016013. https://doi.org/10.1088/1752-7163/aa5cc5.

(12) Lan, J.; Gisler, A.; Bruderer, T.; Sinues, P.; Zenobi, R. Monitoring Peppermint Washout in the Breath Metabolome by Secondary Electrospray lonization-High Resolution Mass Spectrometry. J. Breath Res. 2020. https://doi.org/10.1088/1752-7163/ab9f8a.

(13) Hüppe, T.; Lorenz, D.; Wachowiak, M.; Maurer, F.; Meiser, A.; Groesdonk, H.; Fink, T.; Sessler, D. I.; Kreuer, S. Volatile Organic Compounds in Ventilated Critical Care Patients: A Systematic Evaluation of Cofactors. BMC Pulm. Med. 2017, 17 (1), 116. https://doi.org/10.1186/s12890-017-0460-0.

(14) Schubert, J. K.; Miekisch, W.; Birken, T.; Geiger, K.; Nöldge-Schomburg, G. F. E. Impact of Inspired Substance Concentrations on the Results of Breath Analysis in Mechanically Ventilated Patients. Biomarkers 2005, 10 (2-3), 138-152. https://doi.org/10.1080/13547500500050259.

(15) van Velzen, P.; Brinkman, P.; Knobel, H. H.; van den Berg, J. W. K.; Jonkers, R. E.; Loijmans, R. J.; Prins, J. M.; Sterk, P. J. Exhaled Breath Profiles Before, During and After Exacerbation of COPD: A Prospective Follow-Up Study. COPD J. Chronic Obstr. $\begin{array}{lllll}\text { Pulm. } & \text { Dis. } & \text { 2019, } & \end{array}$ https://doi.org/10.1080/15412555.2019.1669550.

(16) Rösch, C.; Kohajda, T.; Röder, S.; von Bergen, M.; Schlink, U. Relationship between Sources and Patterns of VOCs in Indoor Air. Atmos. Pollut. Res. 2014, 5 (1), 129137. https://doi.org/10.5094/APR.2014.016.

(17) Koureas, M.; Kirgou, P.; Amoutzias, G.; Hadjichristodoulou, C.; Gourgoulianis, K.; Tsakalof, A. Target Analysis of Volatile Organic Compounds in Exhaled Breath for Lung Cancer Discrimination from Other Pulmonary Diseases and Healthy Persons. 
Metabolites 2020, 10 (8), 317. https://doi.org/10.3390/metabo10080317.

(18) Boshier, P. R.; Cushnir, J. R.; Priest, O. H.; Marczin, N.; Hanna, G. B. Variation in the Levels of Volatile Trace Gases within Three Hospital Environments: Implications for Clinical Breath Testing. J. Breath Res. 2010, 4 (3), 031001. https://doi.org/10.1088/1752-7155/4/3/031001.

(19) Axel Clausen, P.; Wolkoff, P. Degradation Products of Tenax TA Formed during Sampling and Thermal Desorption Analysis: Indicators of Reactive Species Indoors. Atmos. Environ. 1997, 31 (5), 715-725. https://doi.org/10.1016/S13522310(96)00230-0.

(20) Ibrahim, W.; Wilde, M.; Cordell, R.; Salman, D.; Ruszkiewicz, D. M.; Brynt, L.; Richardson, M.; Free, R.; Zhao, B. Assessment of Breath Volatile Organic Compounds in Acute Cardio-Respiratory Breathlessness: A Protocol Describing a Prospective Real World Observational Study. BMJ Open 2019.

(21) Ruszkiewicz, D.; Henderson, B.; Wilkinson, M.; Beauchamp, J.; Holz, O.; Salman, D.; Francesco, F. Di; Langejürgen, J.; Koppen, G.; Pedrotti, M.; Moreno, S.; Slingers, G.; Sinues, P.; Wilde, M.; Zenobi, R.; Zanella, D.; Lomonaco, T.; Franchina, F. A.; GrassinDelyle, S.; Focant, J.-F.; Stefanuto, P.-H.; Cristescu, S.; Fowler, S.; Thomas, C. L. P. A Benchmarking Protocol for Breath Analysis: The Peppermint Breath Experiment. J. Breath Res. Res.

(22) Broadhurst, D.; Goodacre, R.; Reinke, S. N.; Kuligowski, J.; Wilson, I. D.; Lewis, M. R.; Dunn, W. B. Guidelines and Considerations for the Use of System Suitability and Quality Control Samples in Mass Spectrometry Assays Applied in Untargeted Clinical Metabolomic Studies. Metabolomics 2018, $14 \quad$ (6), 72. https://doi.org/10.1007/s11306-018-1367-3.

(23) Hübschmann, H.-J. Handbook of GC/MS : Fundamentals and Applications; Wiley-VCH, 2009.

(24) Alkhalifah, Y.; Phillips, I.; Soltoggio, A.; Darnley, K.; Nailon, W. H.; McLaren, D.; Eddleston, M.; Thomas, C. L. P.; Salman, D. VocCluster: Untargeted Metabolomics Feature Clustering Approach for Clinical Breath Gas Chromatography - Mass Spectrometry Data. Anal. Chem. 2019, acs.analchem.9b03084. https://doi.org/10.1021/acs.analchem.9b03084.

(25) L. Eriksson, E. Johansson, N. Kettaneh-Wold, J.Trygg, C. Wikström, and S. W. Multiand Megavariate Data Analysis Part I: Basic Principles and Applications; 2006. https://doi.org/10.1002/cem.713.

(26) Eriksson, L.; Byrne, T.; Johansson, E.; Trygg, J.; Wikström, C. Multi- and Megavariate Data Analysis Basic Principles and Applications - Umetrics, 3rd ed.; MKS Umetrics AB: Malmo Sweden, 2013.

(27) Salek, R. M.; Steinbeck, C.; Viant, M. R.; Goodacre, R.; Dunn, W. B. The Role of 
506

507

508

509

510

511

512

513

514

515

516

517

518

519

520

521

522

523

524

525

526

527

528

529

530

531

532

533
Reporting Standards for Metabolite Annotation and Identification in Metabolomic Studies. Gigascience 2013, 2 (1), 13. https://doi.org/10.1186/2047-217X-2-13.

(28) Westhoff, M.; Litterst, P.; Maddula, S.; Bödeker, B.; Rahmann, S.; Davies, A. N.; Baumbach, J. I. Differentiation of Chronic Obstructive Pulmonary Disease (COPD) Including Lung Cancer from Healthy Control Group by Breath Analysis Using Ion Mobility Spectrometry. Int. J. Ion Mobil. Spectrom. 2010, 13 (3-4), 131-139. https://doi.org/10.1007/s12127-010-0049-2.

(29) Zimmermann, D.; Hartmann, M.; Moyer, M. P.; Nolte, J.; Baumbach, J. I. Determination of Volatile Products of Human Colon Cell Line Metabolism by GC/MS Analysis. Metabolomics 2007, 3 (1), 13-17. https://doi.org/10.1007/s11306-006-0038-y.

(30) Mansoor, J. K.; Schelegle, E. S.; Davis, C. E.; Walby, W. F.; Zhao, W.; Aksenov, A. A.; Pasamontes, A.; Figueroa, J.; Allen, R. Analysis of Volatile Compounds in Exhaled Breath Condensate in Patients with Severe Pulmonary Arterial Hypertension. PLoS One 2014, 9 (4), e95331. https://doi.org/10.1371/journal.pone.0095331.

(31) Jia, Z.; Zhang, H.; Ong, C. N.; Patra, A.; Lu, Y.; Lim, C. T.; Venkatesan, T. Detection of Lung Cancer: Concomitant Volatile Organic Compounds and Metabolomic Profiling of Six Cancer Cell Lines of Different Histological Origins. ACS omega 2018, 3 (5), 51315140. https://doi.org/10.1021/acsomega.7b02035.

(32) Nakhleh, M. K.; Haick, H.; Humbert, M.; Cohen-Kaminsky, S. Volatolomics of Breath as an Emerging Frontier in Pulmonary Arterial Hypertension. Eur. Respir. J. 2017, 49 (2). https://doi.org/10.1183/13993003.01897-2016.

(33) Weisel, C.; Yu, R.; Roy, A.; Georgopoulos, P. Biomarkers of Environmental Benzene Exposure. Environ. Health Perspect. 1996, 104 Suppl (Suppl 6), 1141-1146. https://doi.org/10.1289/ehp.961041141.

(34) Kumar, S.; Huang, J.; Abbassi-Ghadi, N.; Mackenzie, H. A.; Veselkov, K. A.; Hoare, J. M.; Lovat, L. B.; Španěl, P.; Smith, D.; Hanna, G. B. Mass Spectrometric Analysis of Exhaled Breath for the Identification of Volatile Organic Compound Biomarkers in Esophageal and Gastric Adenocarcinoma. Ann. Surg. 2015, 262 (6), 981-990. https://doi.org/10.1097/SLA.0000000000001101.

(35) Ruszkai, Z.; Bokrétás, G. P.; Bartha, P. T. Sevoflurane Therapy for Life-Threatening Acute Severe Asthma: A Case Report. Can. J. Anaesth. 2014, 61 (10), 943-950. https://doi.org/10.1007/s12630-014-0213-y.

(36) Schutte, D.; Zwitserloot, A.; Hoog, M. d.; Houmes, R.; Draaisma, J.; Lemson, J. Sevoflurane Therapy for Life Threatening Asthma in Children. Arch. Dis. Child. 2012, 97 (Suppl 2), A123-A124. https://doi.org/10.1136/archdischild-2012302724.0419.

(37) Ghimenti, S.; Di Francesco, F.; Onor, M.; Stiegel, M. A.; Trivella, M. G.; Comite, C.; Catania, N.; Fuoco, R.; Pleil, J. D. Post-Operative Elimination of Sevoflurane Anesthetic 
and Hexafluoroisopropanol Metabolite in Exhaled Breath: Pharmacokinetic Models for Assessing Liver Function. J. Breath Res. 2013, 7 (3), 036001. https://doi.org/10.1088/1752-7155/7/3/036001.

(38) Fenske, J. D.; Paulson, S. E.; Fenske, P. Human Breath Emissions of VOCs. J. Air Waste Manage. Assoc.

1999 , 49

(5), 594-598.

539

540 https://doi.org/10.1080/10473289.1999.10463831.

(39) Williams, J.; Stönner, C.; Wicker, J.; Krauter, N.; Derstroff, B.; Bourtsoukidis, E.; Klüpfel, T.; Kramer, S. Cinema Audiences Reproducibly Vary the Chemical Composition of Air 541

542 during Films, by Broadcasting Scene Specific Emissions on Breath. Sci. Rep. 2016, 6

543

544 (0000), 4-7. https://doi.org/10.1038/srep25464.

545

(40) Veres, P. R.; Faber, P.; Drewnick, F.; Lelieveld, J.; Williams, J. Anthropogenic Sources of VOC in a Football Stadium: Assessing Human Emissions in the Atmosphere. Atmos. Environ. 2013, 77, 1052-1059. https://doi.org/10.1016/j.atmosenv.2013.05.076.

(41) Phillips, M.; Greenberg, J.; Awad, J. Metabolic and Environmental Origins of Volatile 548 Organic Compounds in Breath. J. Clin. Pathol. 1994, 47 (11), 1052-1053. 549 https://doi.org/10.1136/jcp.47.11.1052.

550

551

552

553

(42) Martin, H. J.; Turner, M. A.; Bandelow, S.; Edwards, L.; Riazanskaia, S.; Thomas, C. L. P. Volatile Organic Compound Markers of Psychological Stress in Skin: A Pilot Study. J. Breath Res. 2016, 10 (4), 046012. https://doi.org/10.1088/17527155/10/4/046012. 
557 THE VARIABILITY OF VOLATILE ORGANIC COMPOUNDS IN CLINICAL ENVIRONMENTS.

558 Dahlia Salmana, Wadah Ibrahimb,c, Amisha Kanabara, Bo Zhao ${ }^{b, c}$, Amisha Singapurib,c, Michael 559 Wilded, Rebecca L Cordelld, Teresa McNallyb, Dorota Ruszkiewicza, Andria Hadjitheklia, Robert Freeb,c, 560 Neil Greeningb,c, Erol A Gaillardb, Caroline Beardsmoreb, Paul Monksd, Chris Brightlingb,c, Salman 561 Siddiquib,c, C L Paul Thomas ${ }^{a *}$ On behalf of the EMBER consortium

$562 *$ *orresponding author: C.L.P.Thomas@lboro.ac.uk

563 a Department of Chemistry, Loughborough University, Loughborough, LE11 3TU, UK.

564 b College of Life Sciences, Department of Respiratory Sciences, University of Leicester, $565 \quad$ University Road, Leicester LE1 7RH

566 c Leicester NIHR Biomedical Research Centre (Respiratory theme), Glenfield Hospital, Groby $567 \quad$ Road, Leicester LE3 9QP

568 d Department of Chemistry, University of Leicester, University Road, Leicester, LE1 7RH

569 


\section{FIGURES}

572

573

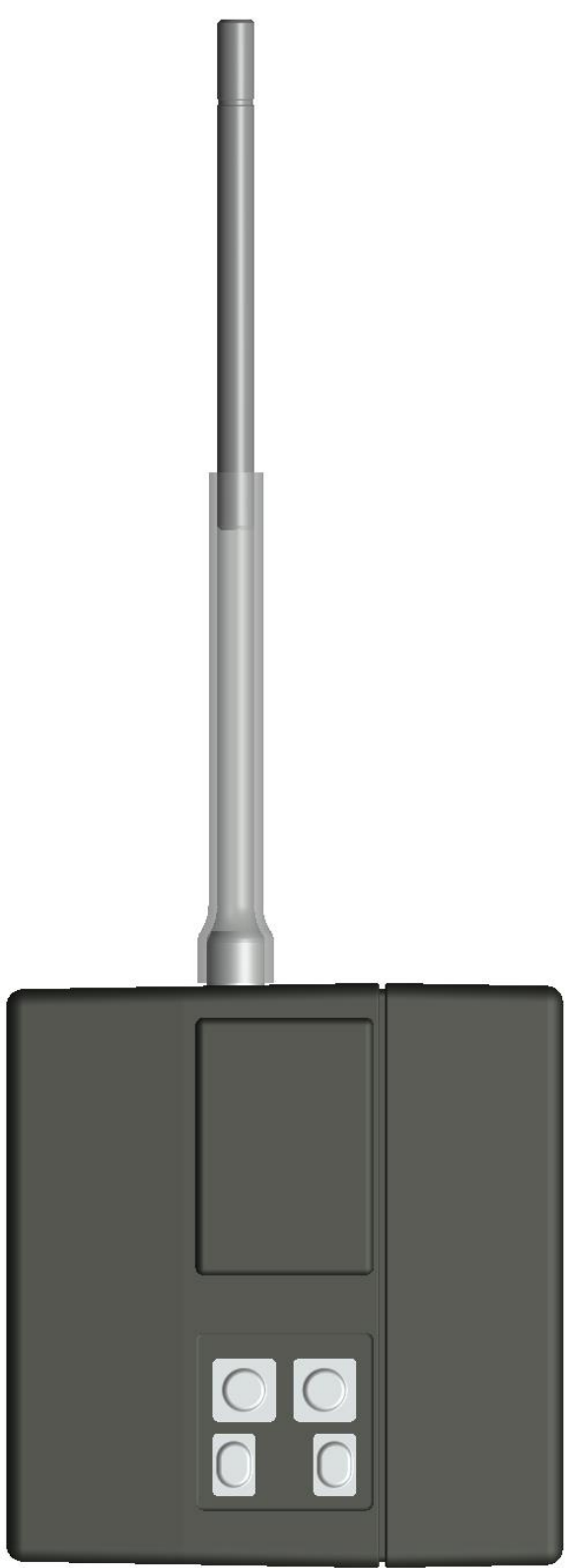

574 Figure S7: The Escort Elf pump attached to a Tenax ${ }^{\circledR} /$ Carbotrap 1TD hydrophobic adsorbent

575 tube to continuously sample $(500 \mathrm{~cm} 3 \mathrm{~min}-1)$ the indoor air of the clinic/ward

576 for $120 \mathrm{~s}$.

577 

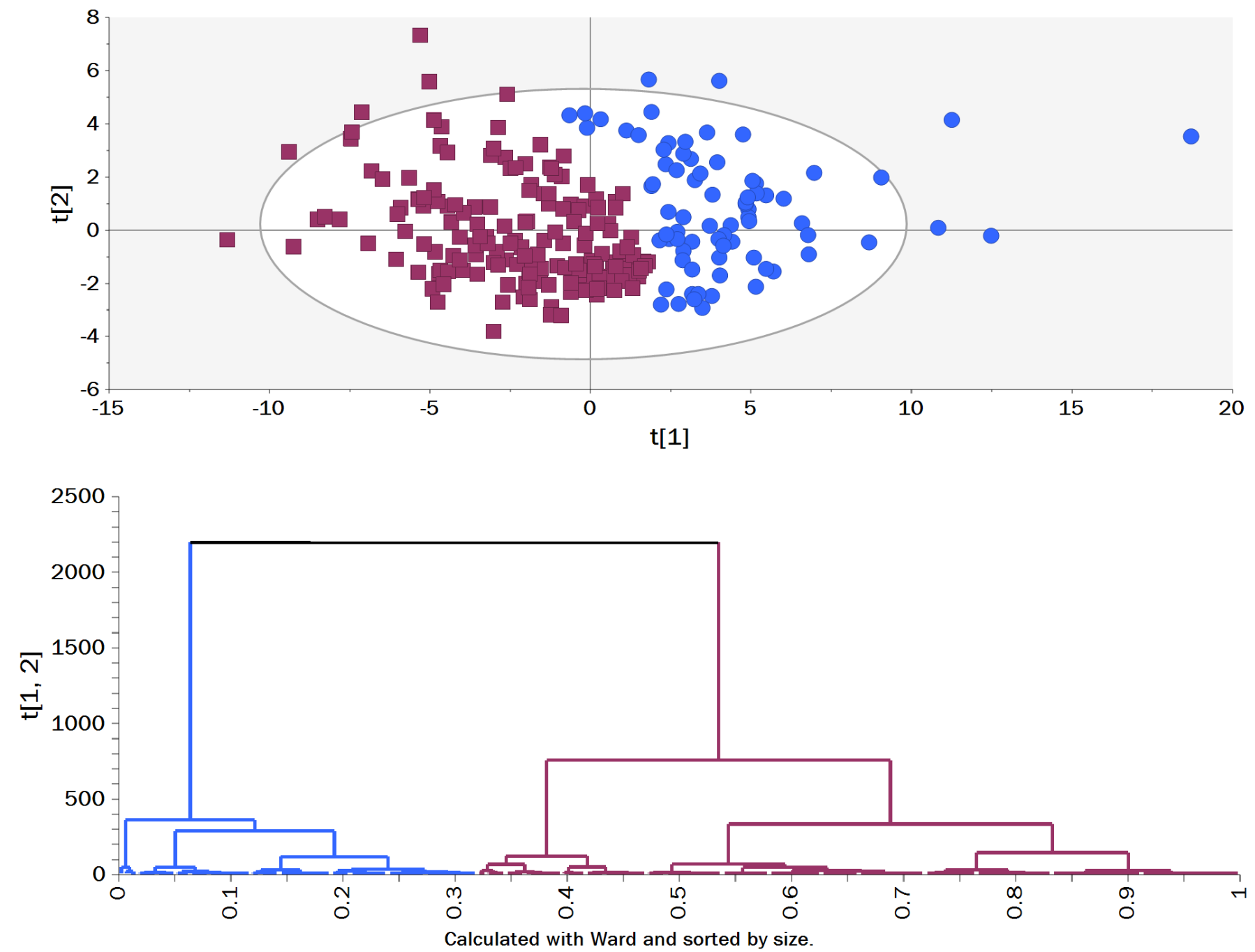

Figure S8: PCA (top) and its associate dendrogram (bottom) to examine the seasonality effects on the environmental Vocs profile in the two clinics. Winter and summer groups are coloured with blue and red, respectively. 


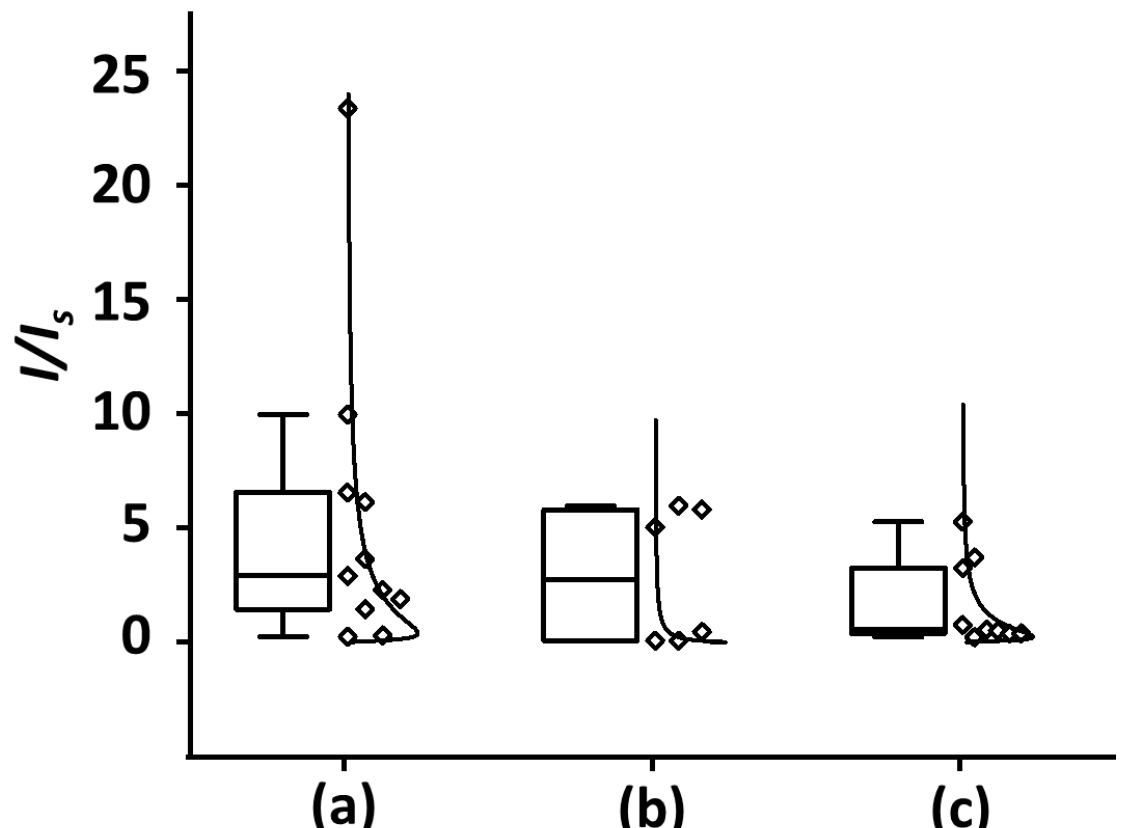

581

582 Figure S9 Box plots and lognormal distribution curves for (a) Sevoflurane ( $\mathrm{m} / \mathrm{z} 131$, 583 retention index 661, mean 3.09, sd 5.51) and its two metabolites (b) 2Propanone, 1,1,1,3,3,3-hexafluoro $(\mathrm{m} / \mathrm{z} 69$, retention index 655 , mean 0.92 , sd 2.04) and (c) and 2-Propanol, 1,1,1,3,3,3-hexafluoro ( $\mathrm{m} / \mathrm{z} 51$, retention index 670 , mean 0.79 , sd 1.48) 


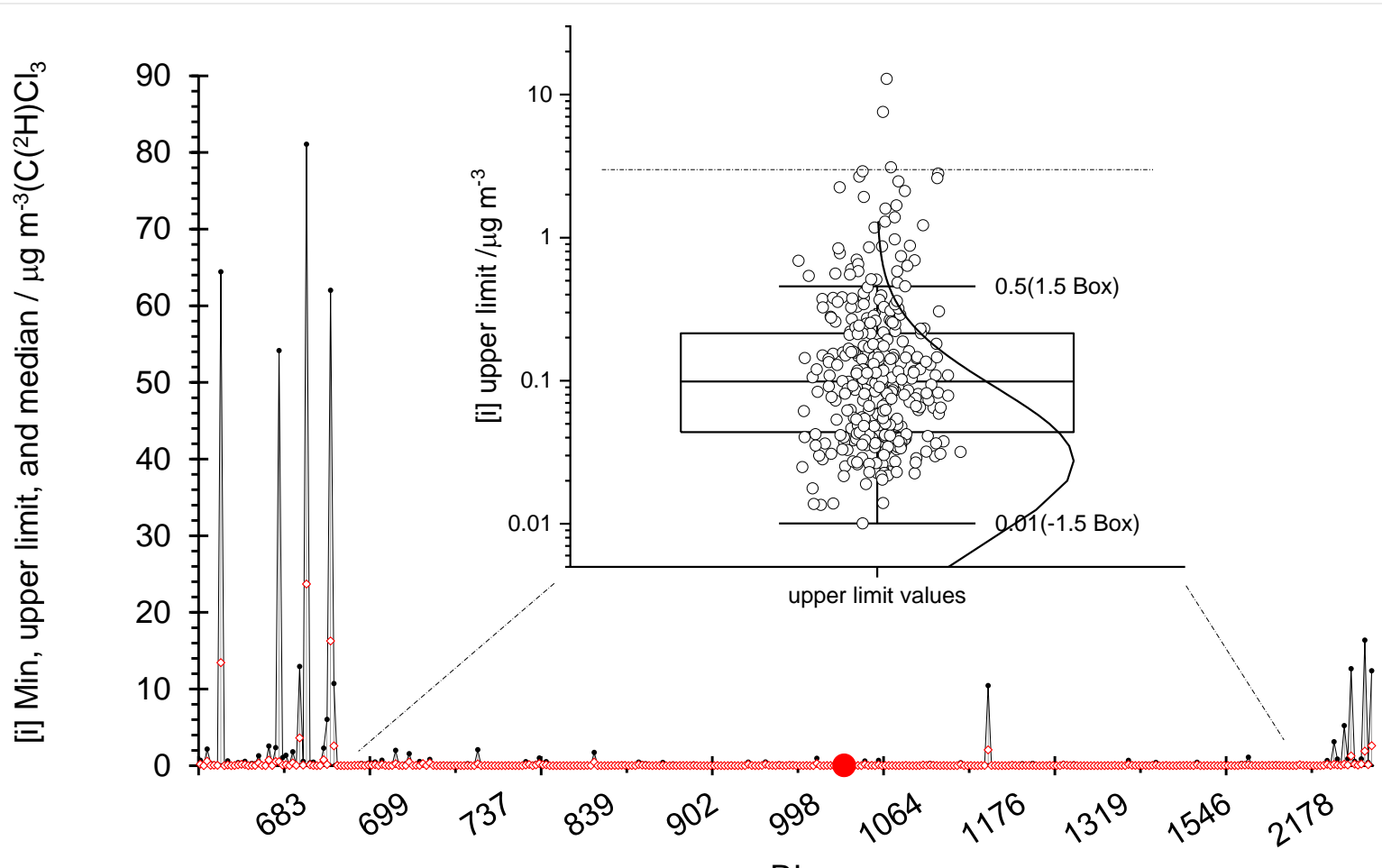

$\mathrm{RI}$

Figure S10 Further detail on Figure 6 comparing the minimum, median (red diamonds) and upper limit of observed concentrations across the 328 most frequently observed (frequency $>5 \%$ ) VOC over the duration of the study. The octanal entry is denoted by the solid red circle. The concentrations of these compounds spanned a range of 2 to 3 orders of magnitude and the Q3+1.5 IQR was 0.5) The inset box whisper plot consolidates the upper limits of the 328 VOC. A working threshold of $3 \mathrm{\mu g} \mathrm{m}^{-3}$ (expressed as a $\mathrm{C}\left({ }^{2} \mathrm{H}\right) \mathrm{Cl}_{3}$ equivalent and indicated by the dotted line) may be reliably applied across the RI range of RI 700 to RI 1900. This excludes volatile solvents (RI less than 700) and heavier waxes associated with PPE production (RI greater than 1900), 
603 Table S2: TD-GC-MS operational conditions

\begin{tabular}{|c|c|c|c|c|c|}
\hline $\begin{array}{l}\text { Thermal desorption } \\
\text { Parameters }\end{array}$ & Setting & $\begin{array}{l}\text { Gas chromatography } \\
\text { Parameters }\end{array}$ & Setting & $\begin{array}{l}\text { Mass spectrometer } \\
\text { Parameters }\end{array}$ & Setting \\
\hline $\begin{array}{l}t \text { Primary desorption } \\
F \text { Primary desorption } \\
T \text { Primary desorption } \\
T \text { Secondary desorption } \\
F \text { Secondary desorption } \\
T \text { Secondary desorption } \\
F \text { Cold trap } \\
T \text { cold trap } \\
\left(\frac{\delta T}{\delta t}\right)_{\text {trap }} \\
T \text { Trap high } \\
t \text { Trap hold } \\
T \text { Flow path } \\
\text { Mode }\end{array}$ & $\begin{array}{l}1 \mathrm{~min} \\
40 \mathrm{~cm}^{3} \mathrm{~min}^{-1} \\
300^{\circ} \mathrm{C} \\
5 \mathrm{~min} \\
50 \mathrm{~cm}^{3} \mathrm{~min}^{-1} \\
300^{\circ} \mathrm{C} \\
20 \mathrm{~cm}^{3} \mathrm{~min}^{-1} \\
-10^{\circ} \mathrm{C} \\
\mathrm{Max}^{\circ} \mathrm{C} \mathrm{min}^{-1} \\
300^{\circ} \mathrm{C} \\
5 \mathrm{~min}^{\circ} \\
200^{\circ} \mathrm{C} \\
\text { Spitless }\end{array}$ & $\begin{array}{l}F \text { He carrier gas } \\
T \text { Initial } \\
t \text { Initial hold } \\
T \text { program } \\
T \text { End } \\
t \text { End hold } \\
t \text { Total run } \\
T \text { Post run } \\
t \text { Post run }\end{array}$ & $\begin{array}{l}2 \mathrm{~cm}^{3} \mathrm{~min}^{-1} \\
40^{\circ} \mathrm{C} \\
0 \mathrm{~min} \\
5^{\circ} \mathrm{C} \mathrm{min}^{-1} \text { to } 300^{\circ} \mathrm{C} \\
300^{\circ} \mathrm{C} \\
0 \mathrm{~min} \\
60 \mathrm{~min} \\
45^{\circ} \mathrm{C} \\
0 \mathrm{~min}\end{array}$ & $\begin{array}{l}\text { Scan type } \\
\text { Mass range } \\
\text { lonisation type } \\
\boldsymbol{v} \text { scan } \\
\boldsymbol{T} \text { line temperature } \\
\boldsymbol{T} \text { Quadrupole } \\
\boldsymbol{T} \text { Manifold } \\
t \text { Solvent delay }\end{array}$ & $\begin{array}{l}\text { Full scan }(+v e) \\
40 \text { to } 550 \mathrm{~m} / \mathrm{z} \\
\mathrm{El} \\
3 \mathrm{~Hz} \\
300^{\circ} \mathrm{C} \\
150^{\circ} \mathrm{C} \\
230^{\circ} \mathrm{C} \\
5 \mathrm{~min}\end{array}$ \\
\hline
\end{tabular}

604 Note: $\mathbf{t}$, time; F, flow; $\mathbf{T}$, temperature; and $\mathbf{v}$, frequency. 
Table S3: A list of volatile organic compounds that were detected in the environmental air of both hospitals and were found to be higher in the winter seasons than summer.* is for compounds that were higher in winter by 1.5 -foldhowever not statistically different following a one-tail t-test. fIdentification of ethanol is qualified in that the full mass spectrum was not captured within the scan range of the method.

$\overline{\boldsymbol{I}_{\boldsymbol{W}}} / \boldsymbol{I}_{\mathrm{IS}}$ : mean intensity ratio to $\mathrm{C}\left({ }^{2} \mathrm{H}\right) \mathrm{Cl}_{3}$ internal standard in winter; $\boldsymbol{S}_{\boldsymbol{W}}$ standard deviation (winter); $\overline{\boldsymbol{I}}_{\boldsymbol{S}} / \boldsymbol{I}_{\mathrm{IS}}$ : mean intensity ratio to $\mathrm{C}\left({ }^{2} \mathrm{H}\right) \mathrm{Cl}_{3}$ internal standard in summer; $\boldsymbol{S}_{\boldsymbol{S}}$ standard deviation (summer); $\overline{\boldsymbol{I}_{W}} / \overline{\boldsymbol{I}_{\boldsymbol{S}}}$ fold change in abundance between winter and summer; DoF: degrees of freedom

\begin{tabular}{|c|c|c|c|c|c|c|c|c|c|c|}
\hline \multirow{2}{*}{ Compound } & \multicolumn{2}{|c|}{ Winter } & \multicolumn{2}{|c|}{ Summer } & \multirow{2}{*}{$\overline{I_{W}} / \overline{I_{S}}$} & \multirow{2}{*}{$\begin{array}{c}\mathbf{t} \\
\text { Stat }\end{array}$} & \multirow{2}{*}{$\begin{array}{c}t_{c r i t} \\
\text { 1-tail }\end{array}$} & \multirow{2}{*}{$\begin{array}{c}P \leq t \\
1 \text {-tail }\end{array}$} & \multirow{2}{*}{ DoF } & \multirow{2}{*}{ Violin plots } \\
\hline & $\overline{\boldsymbol{I}_{W}} / \boldsymbol{I}_{\mathrm{IS}}$ & $S_{W}$ & $\overline{I_{S}} / I_{\mathrm{IS}}$ & $S_{S}$ & & & & & & \\
\hline
\end{tabular}

Ethanol

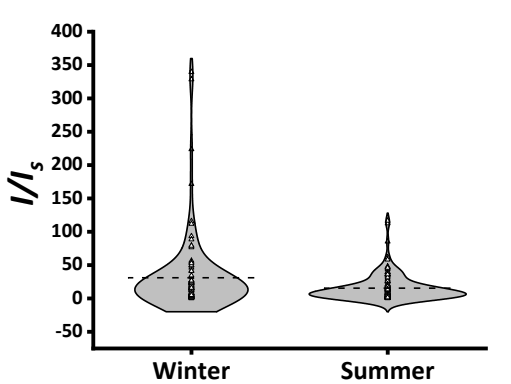

Cyclohexanone

0.73

0.90

0.47

0.38

1.55

1.79

1.67

0.038

62

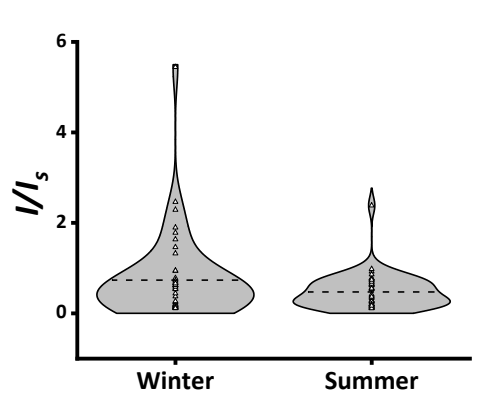




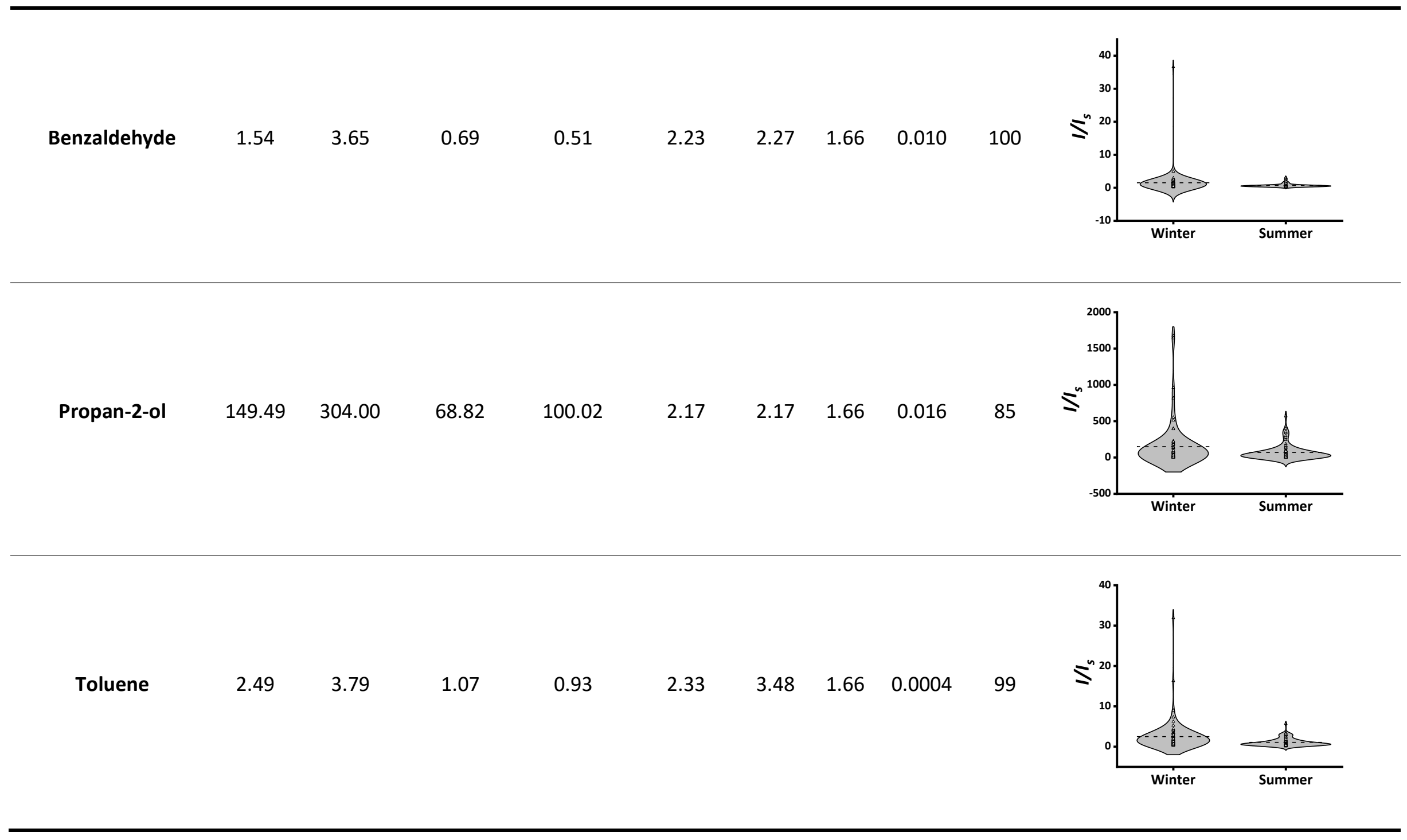




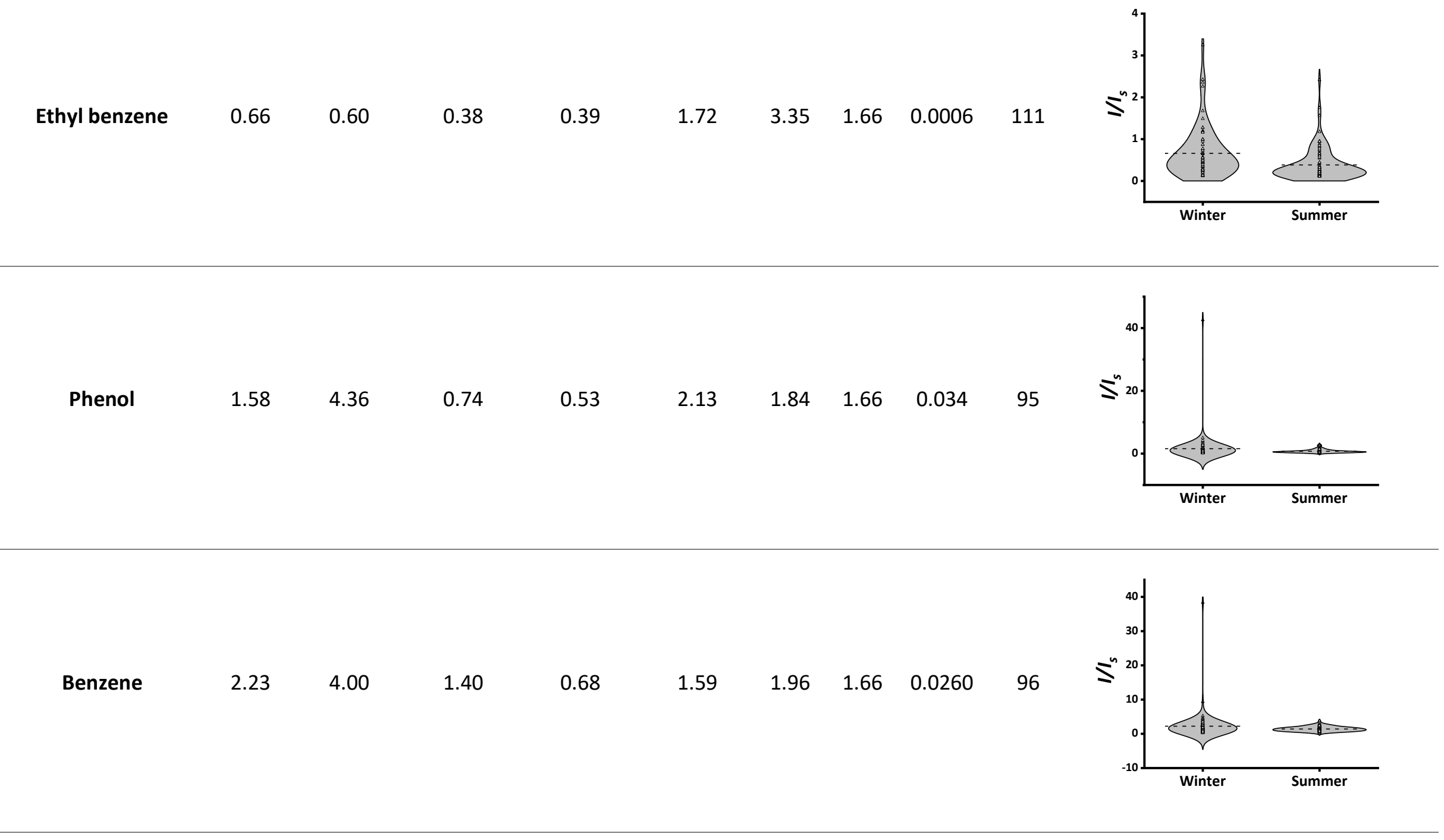




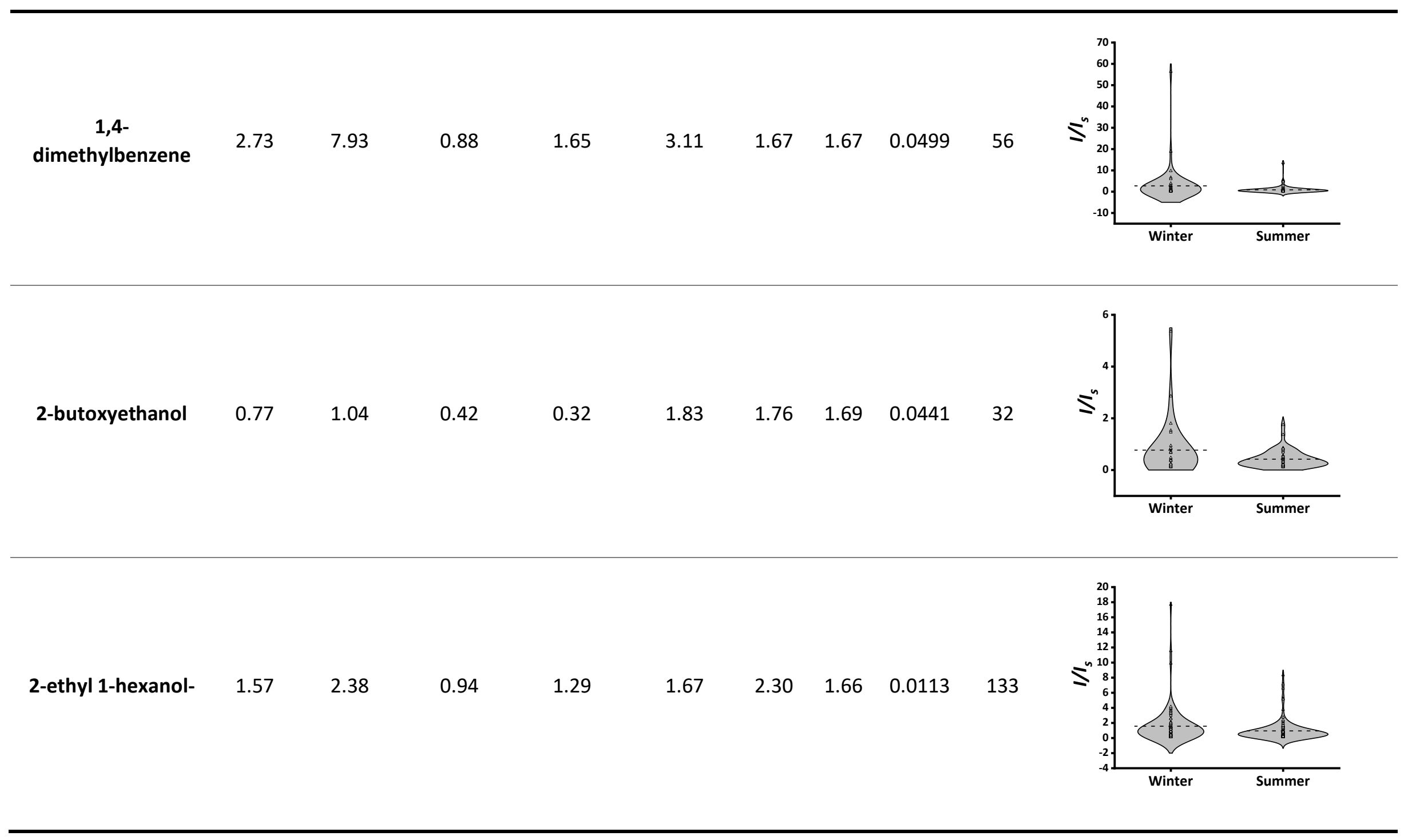


(6S)-2,6-Dimethyl-

7-octen-2-ol

1.11

2.61

0.48

1.68

0.0491

51

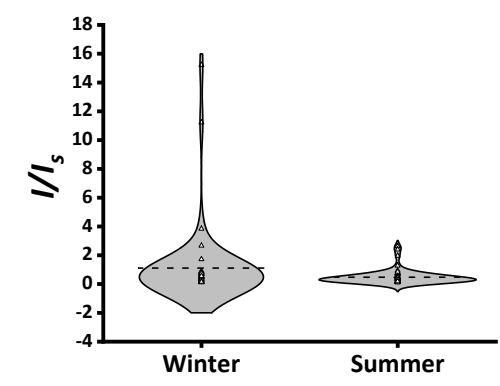

9.36

22.37

4.88

20.75

1.92

1.49

1.65

0.068

185

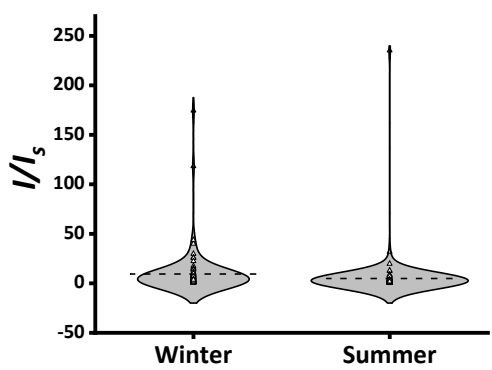

2,5-

Cyclohexadiene-

1,4-dione, 2,5-

4.65

9.47

2.16

8.17

2.15

1.13

1.68

0.130

50

diphenyl- *

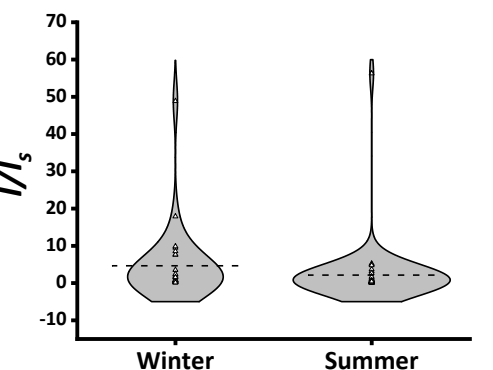




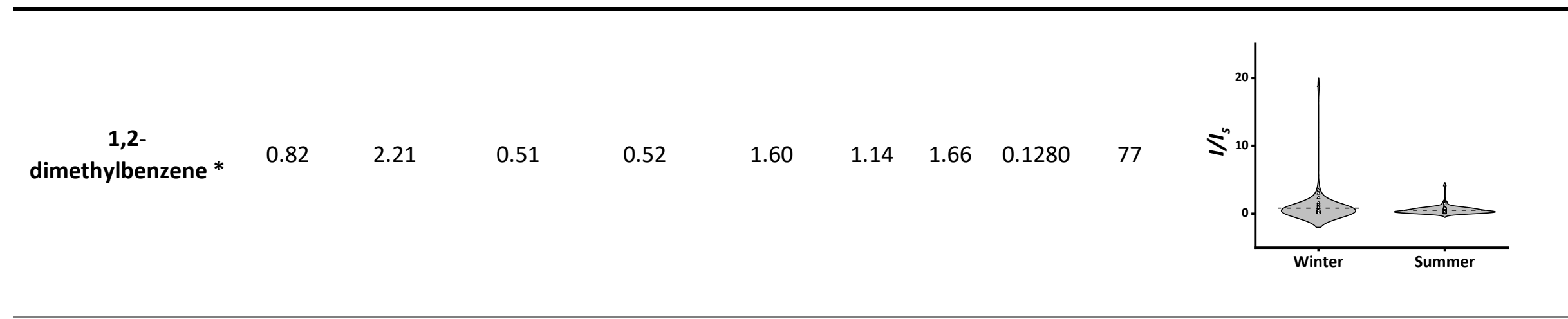

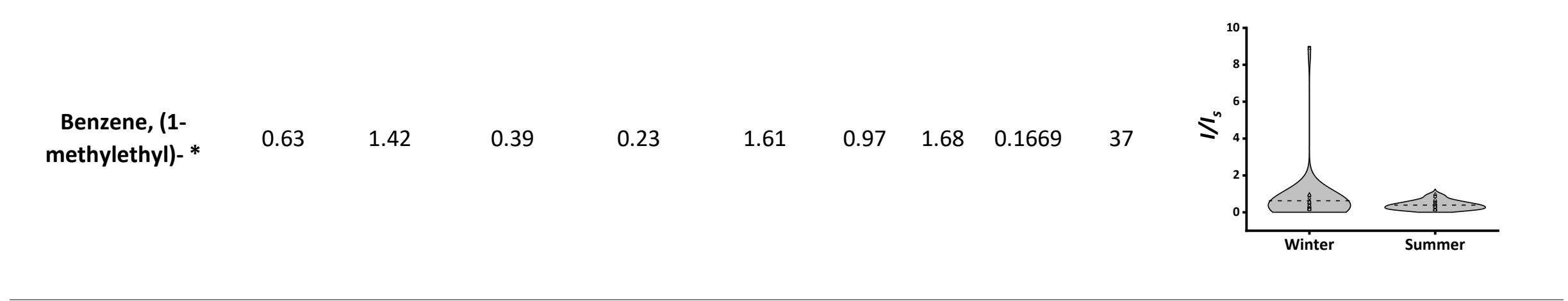

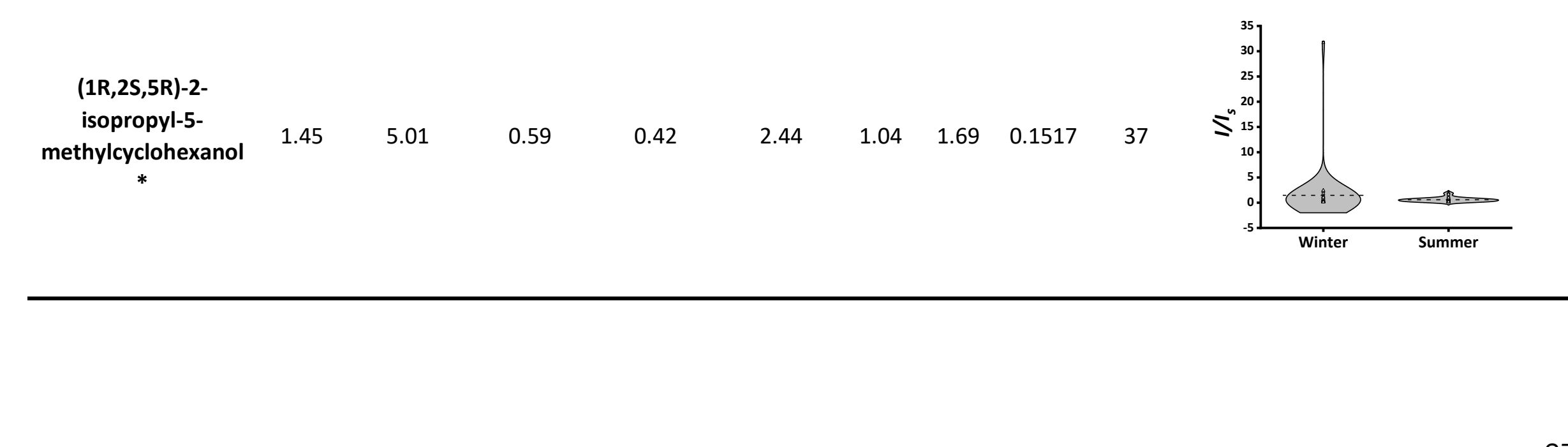

